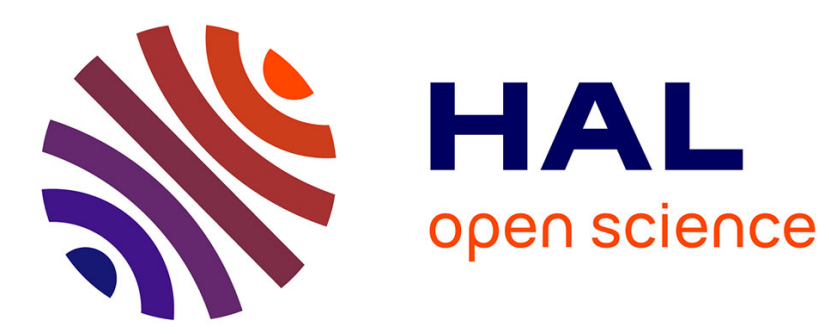

\title{
Fibers for hearts: A critical review on electrospinning for cardiac tissue engineering
}

\author{
Maria Kitsara, Onnik Agbulut, Dimitrios Kontziampasis, Yong Chen,
} Philippe Menasché

\section{- To cite this version:}

Maria Kitsara, Onnik Agbulut, Dimitrios Kontziampasis, Yong Chen, Philippe Menasché. Fibers for hearts: A critical review on electrospinning for cardiac tissue engineering. Acta Biomaterialia, 2017, 48, pp.20-40. 10.1016/j.actbio.2016.11.014 . hal-01628334

\section{HAL Id: hal-01628334 \\ https://hal.sorbonne-universite.fr/hal-01628334}

Submitted on 3 Nov 2017

HAL is a multi-disciplinary open access archive for the deposit and dissemination of scientific research documents, whether they are published or not. The documents may come from teaching and research institutions in France or abroad, or from public or private research centers.
L'archive ouverte pluridisciplinaire HAL, est destinée au dépôt et à la diffusion de documents scientifiques de niveau recherche, publiés ou non, émanant des établissements d'enseignement et de recherche français ou étrangers, des laboratoires publics ou privés. 


\title{
Fibers for hearts: A critical review on electrospinning for cardiac tissue
}

\section{engineering}

\author{
Maria Kitsara $^{\mathrm{a}, *}$, Onnik Agbulut ${ }^{\mathrm{b}}$, Dimitrios Kontziampasis ${ }^{\mathrm{c}}$, Yong Chen ${ }^{\mathrm{d}, \mathrm{e}}$, Philippe Menaschéf ${ }^{\mathrm{f}, \mathrm{g}, *}$ \\ a Instituto de Microelectrónica de Barcelona, IMB-CNM (CSIC), Campus Universidad Autónoma de Barcelona, 08193 Bellaterra, Barcelona, Spain \\ ${ }^{\mathrm{b}}$ Sorbonne Universités, UPMC Univ Paris 06, Institut de Biologie Paris-Seine (IBPS), UMR CNRS 8256, Biological Adaptation and Ageing, 75005 Paris, France \\ 'School of Chemical and Process Engineering, Engineering Department, University of Leeds, LS2 9JT Leeds, UK \\ ${ }^{\mathrm{d}}$ Ecole Normale Supérieure-PSL Research University, Sorbonne Universités, UPMC Univ Paris 06, UMR CNRS 8640, PASTEUR, 75005 Paris, France \\ e Institute for Integrated Cell-Material Science, Kyoto University, Kyoto 606-8507, Japan \\ ${ }^{\mathrm{f}}$ Université Sorbonne Paris Cité, Univ Paris Descartes; INSERM U970, 75015 Paris, France \\ ${ }^{\mathrm{g}}$ Assistance Publique-Hôpitaux de Paris, Hôpital Européen Georges Pompidou, Department of Cardiovascular Surgery, 75015 Paris, France
}

Keywords:

Electrospinning

Tissue engineering

Cardiac cells

Heart therapy

Biopolymers

Functional scaffold

Surface modification

\begin{abstract}
A B S T R A C T
Cardiac cell therapy holds a real promise for improving heart function and especially of the chronically failing myocardium. Embedding cells into 3D biodegradable scaffolds may better preserve cell survival and enhance cell engraftment after transplantation, consequently improving cardiac cell therapy compared with direct intramyocardial injection of isolated cells.

The primary objective of a scaffold used in tissue engineering is the recreation of the natural 3D environment most suitable for an adequate tissue growth. An important aspect of this commitment is to mimic the fibrillar structure of the extracellular matrix, which provides essential guidance for cell organization, survival, and function. Recent advances in nanotechnology have significantly improved our capacities to mimic the extracellular matrix. Among them, electrospinning is well known for being easy to process and cost effective. Consequently, it is becoming increasingly popular for biomedical applications and it is most definitely the cutting edge technique to make scaffolds that mimic the extracellular matrix for industrial applications.

Here, the desirable physico-chemical properties of the electrospun scaffolds for cardiac therapy are described, and polymers are categorized to natural and synthetic. Moreover, the methods used for improving functionalities by providing cells with the necessary chemical cues and a more in vivo-like environment are reported.
\end{abstract}

\section{Contents}

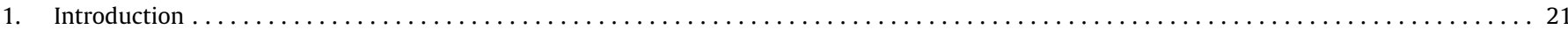

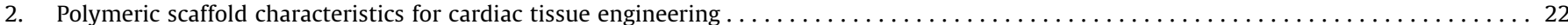

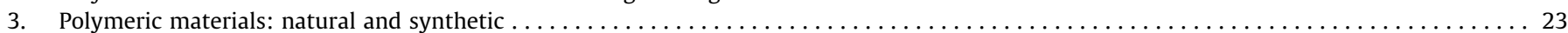

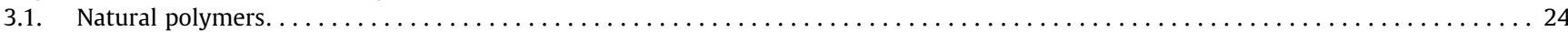

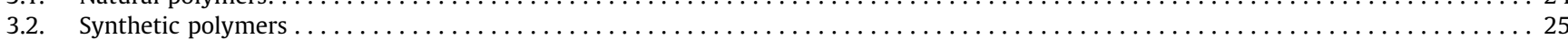

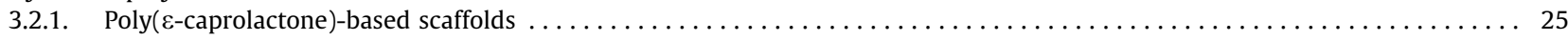

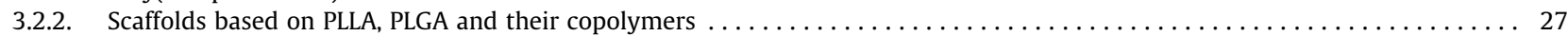

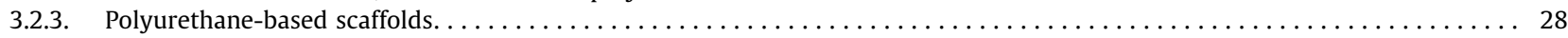

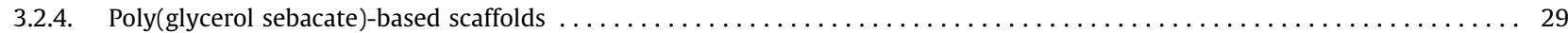

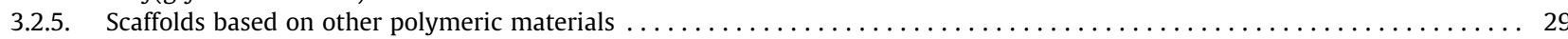

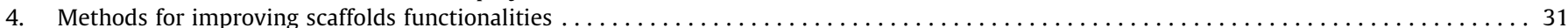

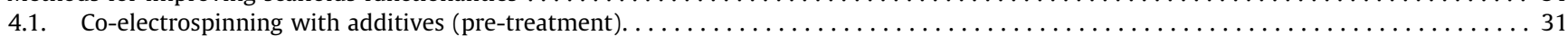

* Corresponding authors at: Instituto de Microelectrónica de Barcelona, IMB-CNM (CSIC), C/del Til.lers, Campus Universidad Autónoma de Barcelona, PC 08193 Bellaterra, Barcelona, Spain (M. Kitsara).

E-mail addresses: kitsara.m@gmail.com, maria.kitsara@imb-cnm.csic.es (M. Kitsara), philippe.menasche@aphp.fr (P. Menasché). 


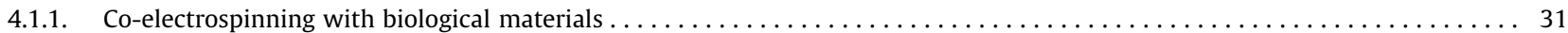

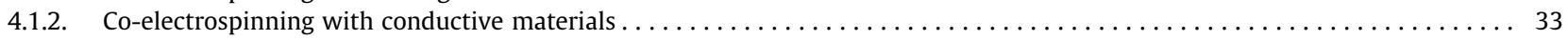

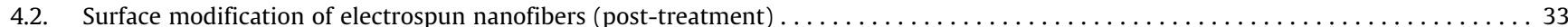

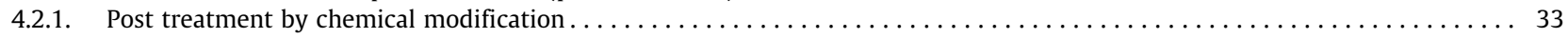

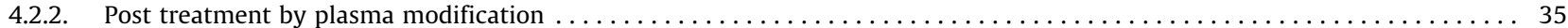

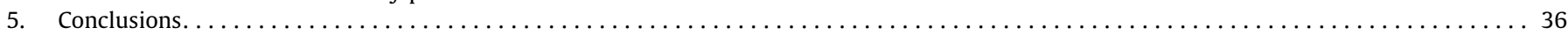

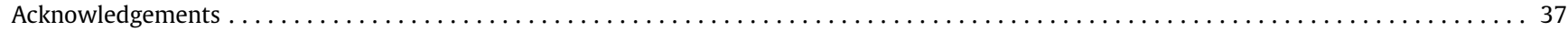

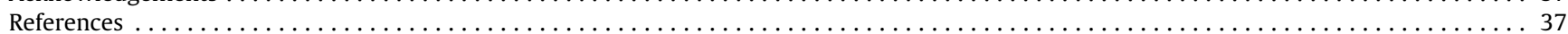

\section{Introduction}

Cardiovascular diseases are the leading cause of disability, limiting the activity and eroding the quality of life of millions of both middle age adults and elderly each year. The Global Burden of Disease study estimated that $29.6 \%$ of all deaths worldwide (15.6 million deaths) were caused by CVDs in 2010 [1]. Among them, more than 7 million are due to ischemic cardiomyopathies which lead mainly to acute myocardial infarction and chronic heart failure [2]. Both the incidence and prevalence of the latter condition are steadily increasing, primarily because early revascularization of myocardial infarctions in industrialized countries results in a higher rate of survival and thus leaves an increasing number of patients at risk of developing a subsequent left ventricular dysfunction.

Although heart transplantation remains the only radical treatment for end-stage heart failure, its indications are limited by organ shortage and the complications associated with major immunosuppression. Mechanical assist devices are still primarily used as bridges to transplant (or recovery) and despite its ability to provide symptomatic relief, biventricular resynchronization fails in $20-30 \%$ of patients [3]. Finally, none of the large trials implemented over the last decade to investigate new drugs has yielded a positive outcome leading to an increased survival of heart failure patients, except for the recent paradigm trial which has reported the benefits of the angiotensin receptor-neprilysin inhibitor LCZ696 [4]. Put together, these observations have provided a rationale for exploring new therapeutic options, among which "regeneration" of the chronically failing heart by stem cells has raised a tremendous interest.

Stem cell therapy aims at restoring some functionality in these scarred regions by providing a new pool of functional contractile elements [8-10]. However, although multiple cell types have been tested experimentally, only skeletal myoblasts and bone marrowderived cells have been assessed in large clinical trials, while cardiac "stem cells", cardiospheres, and adipose-derived stroma cells are still under current investigation [5]. Benefits have been found marginal and most likely due to the paracrine effects of the transplanted cells rather than to a true "regeneration" of the scarred myocardium originating from the graft. A thorough analysis of the reasons for this failure has led to identifying poor cell engraftment as a major contributor to suboptimal outcomes. A major reason for these suboptimal results is likely the low rate of engraftment and high mortality of the transplanted cells into diseased hearts. These two phenomena are caused by a mechanical leakage of cells [6-8] and subsequently worsened by an interplay of biologic factors that include inflammation, ischemia due to poor vascularization of the injected areas, and apoptosis subsequent to detachment of anchorage-dependent cells from their extracellular matrix (ECM), so-called anoikis [9]. The recognition of these contributing factors provides a rationale for embedding cells into 3D biodegradable scaffolds using tissue engineering that may better preserve cell survival and enhance cell engraftment after transplantation, consequently improving cardiac cell therapy compared with direct intramyocardial injection of isolated cells.
Tissue engineering for cellular based transplantation has the following advantages:

1. It can provide a 3D environment to the cells which is more reminiscent of the endogenous cardiac tissue. This patterning is critical for cell survival because it avoids the proteolytic dissociation which is required prior to injection;

2. It allows delivering multiple cell populations: the stem cells under consideration and the "support" cells aimed at providing them with the trophic support required for their survival, differentiation, and migration;

3. It can serve as a platform for growth factors delivery that should positively impact on the grafted cells as well as on the target myocardial environment.

Various tissue-engineered scaffolds have been studied as a cardiac patch for myocardial repair and shown to prevent heart failure by increasing the mechanical strength of the infarct, thereby inhibiting adverse left ventricular remodeling and deterioration of cardiac function [10]. In order to build these 3D constructs, ECM components such as collagen and fibrin can be used to make elastic gels with compositions similar to the body's ECM. Gels in an unpolymerized form can be mixed with cells, and the resulting polymerized matrix creates specific geometric shapes. In Zimmermann et al.'s study, collagen and cardiomyocytes (CMs) were combined into circular molds, which displayed interconnected, beating cells when implanted in infarcted rat hearts [11].

Alternatively, gels and transplantable cells can also polymerize in vivo after injection, permitting the cell-matrix composite to assemble and conform to specific areas of the myocardium. Two separate studies in rats have used skeletal myoblasts in injectable fibrin matrices and embryonic stem cell in collagen matrices, respectively. Both studies reported small decreases in heart failure progression [12,13]. Despite all these different gel setups, some problems remain. The relatively low concentration of CMs limits the force of contraction and once again, adequate vascularization is a challenge unless cells endowed with an angiogenic potential are added to gel mixtures to foster new vessel formation [14].

Another approach has consisted of developing scaffold-free cell sheets obtained by culturing cells onto temperature-sensitive dishes so that, upon cooling, a cell sheet can be collected and overlaid on the diseased area $[15,16]$. The Okano's group, which has pioneered this approach, has reported quite successful outcomes with different cell types (skeletal myoblasts, mesenchymal stem cells (MSCs), cardiac progenitors) [17]. The major advantage of this approach is to avoid any foreign material and the subsequent inflammatory response these materials may trigger. However, these cell sheets also raise practical issues associated with their frailty, the difficulty in safety manipulating them for transfer onto the target region and their propensity to fold and tear. These drawbacks have likely limited their clinical acceptance and fully justify the alternate use of scaffolds that feature better handling characteristics.

As the primary objective of a scaffold used to build a tissue engineered patch is to recreate the natural 3D environment most 
suitable for an adequate cell and tissue growth, an important aspect of this commitment is to mimic the fibrillar structure of the ECM, which provides essential guidance for cell organization, survival, and function. Recent advances in nanotechnology have significantly improved our capacities to mimic the ECM via synthetic techniques originally developed in the fields of microfabrication for microelectronics, microfluidics $[18,19]$ and of membrane separation technologies [20]. Several technologies have been investigated for the fabrication of polymeric scaffolds that mimic this geometry, including; solvent casting/particulate leaching, gas foaming, freeze drying, thermally induced phase separation, photolithography, electrospinning, rapid prototyping techniques such as 3D printing, laser ablation [21-23], except from the decellularization of tissues [24]. Each technique presents advantages and limitations, which have been reported in various review articles [25-27].

Among them, electrospinning is the only one that can be used for industrial applications as it can be effectively up-scaled. This is demonstrated by the continuous growth of electrospinning equipment in the market the last years [28]. Briefly, in the traditional electrospinning, a polymeric solution is fed through a thin needle opposite to a grounded collector and a high voltage is applied to form a jet of the solution that travels from the needle to the collector, where is deposited in the form of dried nanofibers. Many variations have been developed in the last decade for upscaling the process such as needle-free set-ups. The parameters that can be adjusted for the nanofibers formation include the solution properties (viscosity, conductivity, surface tension, molecular weight, concentration and architecture of the polymer), the process parameters (electric potential, flow rate, needle to collector distance, collector shape and composition) and ambient parameters (temperature, humidity). This technique is well known for being easy to process and cost-effective. Consequently, it is becoming increasingly popular for biomedical applications, and it is most definitely the cutting-edge technique to make patches that mimic the ECM for industrial applications [28]. Concerning the material of use for electrospinning, a plethora of polymers have been tested, and most of them use organic solvents. Electrospun nanofiber matrices show morphological similarities to the natural ECM characterized by continuous fibers ranging from nano to micro scale, high surface-to-volume ratio, high porosity and variable poresize distribution. Efforts have also been made to modify nanofiber surfaces with several bioactive molecules to provide cells with the necessary chemical cues and a more in vivo-like environment. In addition, physico-chemical properties of nanofiber matrices can be controlled by manipulating electrospinning parameters to meet the requirements of a particular application [29].

All the above parameters render electrospinning as a very good candidate for the fabrication of scaffolds for cardiac tissue engineering which ideal properties are described in the next section. In the same line, another gain of electrospinning is the variety of nanofibrous structures that can be constructed beyond the morphology of the fiber. The advances in electrospinning set-up and mainly on the type of collector allows for the development of various constructs. For example, modules of electrospinning such as high-speed rotating drum and mandrel collectors can allow for the formation of aligned nanofibers. In addition, collectors designed with a specific structure on demand to the desirable application can work as a master for the formation of a nanofibrous construct of choice, e.g. valves, vessels. For example, electrospun nanofibers of natural biopolymer could be made as a monolayer on a honeycomb microframe and transformed by crosslinking into a mesh with controllable pore sizes, which can more closely mimic the ECMs [30,31]. Of course, there are techniques that are based on computer-aided design (CAD) on which a structure of choice can be fabricated, such as photolithography and 3D printing.
Nevertheless, the main advantage of electrospinning is still the low-cost and the simplicity, renders it as a method that can be adapted even in a biological laboratory as neither specialized engineers nor infrastructure are required (e.g. clean-room facilities in the case of photolithography). It should be stated that all the aforementioned benefits of electrospinning do not apply exclusively to cardiac but also to other areas of tissue engineering. In the light of cardiac tissue engineering on which except from the structural characteristics, electro-mechanical properties (conductivity, elasticity) are of paramount importance, the versatility of electrospinning is an asset since conductive polymers and other additives can be co-electrospun in order to achieve the desired properties.

In the current review an up to date overview of the electrospun scaffolds used so far for cardiac tissue engineering purposes is presented. In the vast majority, cardiac cells were seeded in the scaffolds and their proliferation was evaluated. Among them, the primacy belongs to CMs, as in most of the cases the final target is the treatment of the failing myocardium. Nevertheless, interesting studies, although much less, have been presented for the treatment of other parts of the heart such as the replacement of valves and vessels. The various materials and methods for improving electrospun scaffolds functionalities for cardiac tissue engineering are reviewed.

\section{Polymeric scaffold characteristics for cardiac tissue engineering}

Once the principle of using a scaffold has been adopted, some key parameters need to be determined. These are material composition, surface characteristics, mechanical properties, biocompatibility, degradation rate and cell seeding conditions. The conductivity of the scaffold also appears to play an important role on scaffolds used for cardiac tissue engineering. Production cost and manufacturing conditions compatible with regulatory guidelines for human applications are additional factors that need to be taken into consideration. A comprehensive description of the requirements for a functional cardiac scaffold can be found in review articles such as $[27,32,33]$, whereas herein a synopsis is presented.

Myocardial tissue shows a hierarchical structure with aligned fibrous cells embedded into 3D honeycomb-like micro-patterns formed by both undulated perimysial collagen fibers and different proteins of the ECM $[34,35]$. Thus, a scaffold with fibrous structure is crucial for cell organization, survival, and function of the seeded cardiac cells. To respect anisotropic organization of cardiac tissue and promote development of a functional cardiac syncytium, the fibrous structure needs to be aligned. Several studies demonstrated that the presence of aligned surface facilitates the orientation and organization of CMs [36,37]. Moreover, high surface-to-volume ratio and porosity are indispensable elements for the migration of cells and vascularization.

Regarding to the mechanical properties, it should be taken into consideration that the best scaffold for cardiac tissue regeneration should have a Young's modulus between tens of $\mathrm{kPa}$ and $1 \mathrm{MPa}$, since it has been reported that left ventricular stiffness is about $10-20 \mathrm{kPa}$ at the beginning of diastole and in the range $0.2-$ $0.5 \mathrm{MPa}$ at the end of diastole [38]. Other studies indicated that the Young's modulus of the native heart tissue is in the range of 10-15 kPa [39] while in the case of ischemic tissue, associated with fibrosis, it increases up to $30-50 \mathrm{kPa}$ [40]. Furthermore, Engler et al. using isolating cardiac cells demonstrated that CMs were only able to form mature sarcomeres with regular beating on polyacrylamide gels of about $10 \mathrm{kPa}$ [39]. On softer gels, sarcomeres were less spaced and not fully organized whereas on stiffer gels, myocytes contained more stress fibers and did not display sarcomeres. 
In addition, attention has been driven towards conductivity, another key characteristic of scaffolds for cardiac tissue engineering, given that cardiac cells beat using electric signals which transport through the myocardium. Electrical stimulus is known to control surface properties by controlling surface charge [41]. The same principle is applied to control the attachment, proliferation, and differentiation of cells [42]. Kai et al. measured an increase in connexin 43 (gap junction protein marker involved in electrical signal transmission expression), which is the primary cardiac connexin, in conductive scaffolds comparing to other non-conductive ones [43]. The application of electrical stimulus showed to be in favour of the creation of cardiac tissue in several studies. Tandon et al. showed that by inducing electric stimulation, they promoted the formation of long and well-aligned sarcomeres as well as intercalated discs between aligned $\mathrm{Z}$ line, similarly to that of healthy cardiac tissue [44]. Spontaneous and synchronous beating of cardiac cell when cultured on conductive scaffolds was reported by Dvir et al. [45]. In other studies, the expression of several cardiac-related markers, i.e. Nkx2.5, GATA4, cardiac troponin t, troponin I, connexin 43, desmin, slow myosin and fast myosin were expressed while culturing stem cells (human MSCs and rat bone marrow MSCs) on conductive scaffolds and subjected to electrical stimulation $[46,47]$.

Two other important issues to be taken into consideration are biocompatibility and biodegradability, which allow support of both the appropriate cellular activity and the generation of new tissues. In some cases, bioresorbability is required. Generali et al., described thoroughly the requirements of bioresorbable scaffolds for cardiovascular tissue engineering, and their mechanisms of degradation once they have been implanted [48]. The biomaterials to be used for the elaboration of the scaffolds for heart tissue regeneration need to be compatible with the natural tissue and the cells with a low inflammatory response after implantation. The biomaterials also need to support cell adhesion, differentiation, and proliferation. Natural polymers such as collagen, fibrin and polysaccharides have shown their potential for leading to efficient cell differentiation and enhanced interaction with cardiac cells. However, most of the natural polymers suffer from poor mechanical properties. Synthetic biocompatible/biodegradable polymers such as polyesters are a solution when higher mechanical properties are required. The next section is dedicated to the detailed presentation of the most common electrospun scaffolds made of natural and synthetic polymers, which are used in cardiac tissue engineering.

The last important issue is related to cell seeding conditions. A diverse range of cell seeding techniques has developed over the past decades to promote cell seeding efficiency and consequently long-term graft function. The most common method used in tissue engineering is static seeding, in which a concentrated cell suspension is passively introduced on a scaffold. This technique has several limitations that result in low seeding efficiency and minimal cell penetration into the scaffold. To overcome these limitations, alternate seeding techniques have been developed, including dynamic, magnetic, vacuum, electrostatic, and centrifugal seeding. Each technique presents different advantages, but the final selection of the appropriate method should be made in accordance with the polymer and the scaffold fabrication techniques. Advances in the area of microfabrication and microfluidics lead to the development of different types of bioreactors such as rotating and perfusion-based [49-51].

From all the above, it is evident that the ideal scaffold for cardiac tissue engineering would be the one that combines the following characteristics. (a) Appropriate mechanical properties that match the mechanical properties of the native cardiac tissue (anisotropy, elasticity, contractility, etc.) (b) Appropriate structure that mimics the microenvironement of the native cardiac tissue (fibrous anisotropic alignment characteristic of the myocardium, porosity, nanomorphology, etc.) (c) Appropriate surface (bio)chemistry to promote cardiac cell attachment, proliferation, viability, similar to this of the native cardiac tissue (biocompatibility, wettability, etc.) (d) Appropriate conductivity of the scaffold to allow propagation of electrical stimulation which as discussed above has been proven to have a positive effect on cell behaviour. In the next sections of this study, the methods and approaches used to try to achieve these desired functionalities are presented and discussed.

\section{Polymeric materials: natural and synthetic}

The various requirements for functional cardiac tissue scaffolds have resulted in the development of a plethora of different fabrication approaches and materials utilization. Electrospinning is ranked as the most popular method of fabricating nanofiber scaffolds via synthetic engineering, and it has already shown a number of advantages for tissue engineering purposes [52-55]. A statistical graph of the articles published over the last 12 years using electrospun scaffolds for cardiac tissue engineering applications is depicted in Fig. 1. The first article in the area was published in 2004. From then on, there is an evident increasing interest in this type of bioscaffolds.

Generally speaking, the electrospun nanofibers can be manufactured at low cost from different types of polymers. They can be engineered to have different mechanical and biochemical properties. The biopolymers used are usually categorized into natural and synthetic [56,57]. Both categories have advantages and drawbacks. Natural polymers have intrinsically the necessary biochemical cues for cells attachment and proliferation. Their degradation products are non-toxic and have a low immune response. However, most of this category of polymers requires an extra crosslinking step to become insoluble in aqueousbased solutions such as culture media. The crosslinking may affect not only their 3D structure and porosity, but also their biocompatibility due to the introduction of non-biocompatible chemical agents [58]. In addition, the selection of the correct solvent system is crucial in order to avoid or reduce denaturation. Synthetic polymers have high reproducibility and have a simple quality control process. Moreover, their cost is much lower in comparison to the natural ones and their mechanical properties can be tuned more effectively. But they are missing of biochemical cues which should be introduced either via adding an extra step of functionalization or via combining them with natural polymers.

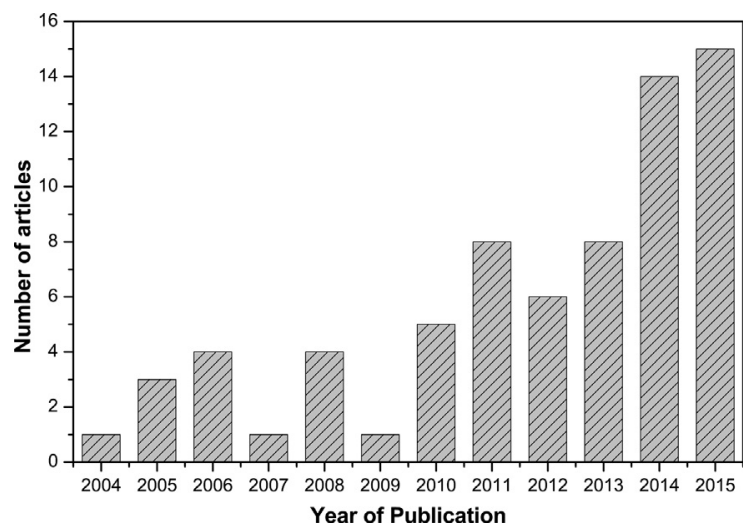

Fig. 1. Articles published over the last 12 years proposing electrospun scaffolds for cardiac tissue engineering. 


\subsection{Natural polymers}

The common natural polymers used in cardiac tissue engineering include collagen, fibrinogen, chitosan, gelatin, elastin and silk.

Collagen is the predominant material out of the natural polymers, its term comes from the Greek words "Кó $\lambda \lambda \alpha$ " and " $\gamma \varepsilon \nu \nu \omega ́$ " that literally means "glue producer" and constitutes the main component of the ECM. Matthews et al. demonstrated that collagen may be used to produce a nearly ideal scaffold for tissue engineering [59], whereas Yow et al. showed that collagen can also be electrospun with other types of polymers, allowing efficient proliferation of human MSCs and maintenance of their multipotency for up to 7 days [60].

The main collagens of interest to cardiovascular engineering are the collagen types I and III. Collagen is an essential component of myocardial connective stroma, which is mainly composed of type I and III fibrillar collagen, and its arrangement may contribute to preserve heart microarchitecture and chamber geometry [61]. Several reports have emphasized that the architecture of myocardial collagen fibers, in particular of the endomysium, may be involved in the regulation of the mechanical activity of the heart [62]. In addition, collagen has a long-standing safety record for medical applications, which should streamline translational processes towards clinics [58].

Clinically approved collagen electrospun scaffolds have been used as supports for H9c2 cardiomyoblasts culture. Among different types of collagen samples, it was found that atelocollagen can produce electrospun fibers of better quality than acid and basic fibrous collagen. Immunostaining for actin and nuclei demonstrated the colonization of the scaffold under optimized crosslinking conditions, where the cardiomyoblasts were spread all over the scaffold and showed a nice structure of their actin filaments [63].

This type of collagen electrospun scaffolds has been recently used for the delivery of human induced pluripotent stem cellderived CMs (hiPS-CM) in a mouse model of dilated cardiomyopathy (DCM) (Fig. 2). Acellular collagen scaffolds were first implanted in both healthy mice and in those where DCM was induced by a cardiac-specific invalidation of serum response factor (SRF). Seven

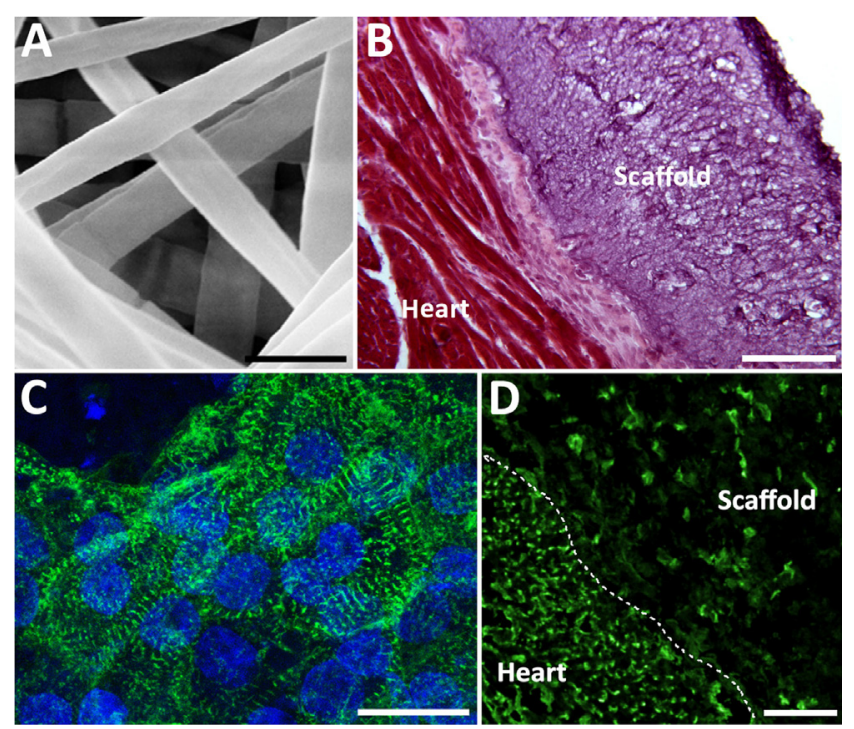

Fig. 2. Improvement of cardiac function in a non-ischemic dilated mouse model following epicardial implantation of the cellularized collagen scaffold. (A) SEM image of the fibrous scaffold; (B) biocompatibility test; (C) cellularisation, immunolabeling against $\alpha$-actinin of hiPS-CM seeded onto a collagen scaffold for 3 days.; (D) presence of new vessels after grafting. Scale bars for (A) $2 \mu \mathrm{m}$; (B) $100 \mu \mathrm{m}$; (C) $20 \mu \mathrm{m}$; (D) $30 \mu \mathrm{m}$. Reprinted with permission from [64]. and fourteen days after implantation, the safety of the scaffold was demonstrated by echocardiography and histological assessments. The subsequent step of implantation of the scaffolds seeded with hiPS-CM in DCM induced mice, using cell-free scaffolds as controls, revealed that after fourteen days, heart function had decreased in controls while it remained stable in the treated mice. This pattern was associated with an increased number of endothelial cells, in line with the greater vascularity of the scaffold. Moreover, a lesser degree of fibrosis consistent with the upregulation of several genes involved in ECM remodeling was observed. These results support the interest of the proposed hiPS-CM seeded electrospun scaffold for the stabilization of the DCM outcome with potential for its clinical use in the future [64].

Fibrinogen is a glycoprotein, synthesized by the liver and found freely circulating in the bloodstream which plays a major role in clotting. Fibrinogen has proved to induce improved cellular interactions and scaffold remodeling compared to synthetic scaffolds. It has the ability to bind with high affinity to functional vascular endothelial growth factor (VEGF), fibroblast growth factor (FGF), and a number of other cytokines [65]. Even if the ability to create fibrinogen nanofibers by electrospinning has been demonstrated, more studies are required for their in vitro cellular interactions behaviour. As a first study, McManus et al. cultured neonatal rat cardiac fibroblasts onto fibrinogen electrospun scaffolds. Those cultures were treated to regulate scaffold degradation by either supplementing serum-containing media with aprotinin or crosslinking the scaffolds with glutaraldehyde vapor. Cell culture demonstrated that fibroblasts readily migrate into and remodel electrospun fibrinogen scaffolds with deposition of native collagen [66].

Another natural polymer that exhibits desirable characteristics for tissue engineering is chitin, along with its deacetylated derivative, chitosan. Chitin is the second most abundant polysaccharide after cellulose, and has a similar structure [67]. Chitosan, apart from its biocompatibility, biodegradability, non-toxicity, has low cost. Electrospun chitosan was utilized to provide structural scaffolding characterized by scale and architectural resemblance to the ECM in vivo. Hussain et al. studied ventricular CMs from neonatal rats in various culture conditions (i.e., mono- and cocultures) for their viability and function by using electrospun chitosan-based nanofiber scaffolds [68]. The results demonstrated that the chitosan nanofibers retained their cylindrical morphology in long-term cell cultures and exhibited good cellular attachment and spreading in the presence of the adhesion molecule fibronectin. CM mono-cultures resulted in a loss of CM polarity and islands of non-coherent contractions. However, the CM-fibroblast cocultures resulted in polarized CM morphology and retained their morphology and function for long-term culture. The Cx43 expression in the fibroblast co-culture was higher than in the $\mathrm{CM}$ mono-culture and endothelial cell co-culture. In addition, fibroblast co-cultures demonstrated synchronized contractions involving large tissue-like cellular networks. This first attempt to test chitosan nanofiber scaffolds as a 3D cardiac co-culture model demonstrated that chitosan nanofibers can serve as a potential scaffold that can retain cardiac structure and function.

Elastin is composed of covalently cross-linked molecules of its precursor, tropoelastin, a soluble, non-glycosylated and highly hydrophobic protein. Tropoelastin expression and subsequent elastin synthesis typically occurs in fibroblasts, vascular SMCs, endothelial cells, and chondrocytes [69]. However, very limited studies have been published for electrospun scaffolds containing only elastin for cardiac tissue engineering purposes $[58,70]$. In most of the cases elastin constitutes one part of an electrospun composite as it will be described subsequently.

Silk is composed of a glue-like sericin protein which role is to hold fibers together, and a fibroin filament component which acts 
as the mechanical backbone. Natural silk fibers have tensile strength and yield at fracture values comparable to synthetic polymeric fibers, and can be slowly absorbed in vivo as biocompatible amino acids. In tissue engineering applications, typically silk fibroin is utilized. A blend of silk fibroin and poly (ethylene oxide) (PEO) was used for the fabrication of electrospun fibers, where both human aortic endothelial cells (hAEC) and human coronary artery smooth muscle cells (hCASMC) were seeded [71]. Both hAECs and hCASMCs demonstrated an affinity for the electrospun silk fibroin/PEO. hCASMCs were shown to elongate and align themselves with SF fibers as well as produce native collagen ECM.

Balasubramanian et al. fabricated bio-composite scaffolds by using fibrinogen and gelatin in two different weight ratios and performing cross-linking [Fib/Gel (1:4)-CL; Fib/Gel(2:3)-CL], while cross-linked fibrinogen scaffolds were used as the control sample [72]. The tensile strength and the stiffness values of Fib/Gel(1:4)CL matrices were found to be 0.0125 and $0.46 \mathrm{MPa}$ respectively, which were much similar to the innate properties of the native myocardium. Cell culture studies using human CMs revealed higher cell proliferation on Fib/Gel(1:4)-CL scaffolds compared to Fib/Gel(2:3)-CL scaffolds, which was even higher than the cell proliferation on cross-linked fibrinogen scaffolds. Moreover, the CMs seeded on composite substrates expressed typical functional cardiac proteins such as $\alpha$-actinin, troponin I, connexin- 43 , and myosin heavy chain, thereby raising the possibility of applications in cardiac tissue engineering.

Moreover, a 3D cardiac patch fabricated from albumin fibers has been recently reported [73]. The fabricated aligned and randomly oriented electrospun albumin fibers had improved elasticity and were capable of adsorbing serum proteins, such as laminin, leading to strong cell-matrix interactions. Additionally, due to the functional groups on their backbone, the fibers could be chemically modified with essential biomolecules. Scaffolds culture with rat neonatal CMs induced the assembly of aligned cardiac tissues with high aspect ratio (length-to-diameter ratio) CMs and massive actinin striation, which was more significant in the case of the aligned scaffolds. Compared to synthetic PCL fibrous scaffolds, CMs cultured within aligned or randomly oriented scaffolds formed functional tissues, exhibiting significantly improved function that generated strong contraction forces.

Table 1 summarizes the scaffolds characteristics, in terms of material used, fibers morphology and in vitro/in vivo studies for the case of using natural polymers for electrospinning for cardiac tissue engineering. From the above, it is concluded the significance of adjusting the elasticity of the scaffolds. Regarding to the fibers alignment, only in the case of albumin both aligned and random fibers were tested where the first ones led to improved functional tissues. It is evident that more studies in the future should be performed using aligned structures which better mimic the native cardiac tissue anisotropy as it has been reported in Section 2. The materials with better performance so far proved to be collagen, chitosan, albumin and silk with the latter possessing superior mechanical properties, especially for vascular grafts. The importance of co-culture CMs with fibroblasts is another aspect that should be taken into account for better mimicking of the natural ECM microenvironment and is an indication that research should focus towards this direction.

\subsection{Synthetic polymers}

There is a plethora of synthetic polymers used for the fabrication of electrospun scaffolds, containing not only one polymer but in the vast majority combinations of different ones and/or combinations with natural polymers for the enhancement of their properties. Their main advantage is their electrospinnability and cost effectiveness, but on the other hand treatment/modification of their surface is usually needed for cell culture purposes.

\subsubsection{Poly(E-caprolactone)-based scaffolds}

The results of the literature research have clearly revealed that the synthetic material of choice for the majority of scientists is poly ( $\varepsilon$-caprolactone) (PCL). Shin et al. have shown that PCL fiber meshes of $250 \mathrm{~nm}$ average fiber diameter suspended on a wire ring support attachment and contraction of neonatal rat CMs in vitro [74]. On day 3, CMs start to contract weakly and in an unsynchronized fashion. These contractions become stronger and synchronized as time progresses. CMs adhered, populated the entire scaffold mesh, and stained positively for cardio-specific proteins [75]. This highly porous non-woven PCL mesh functions as a temporary ECM that enables the cells to adhere, spread, proliferate and establish electrical communications between layers creating synchronized beating. This mesh did not restrict the contractile functions of the CMs and the wire ring provides passive tension that supports maturation of the beating CMs, and may improve handling of the construct [76,77].

Howbeit, the high stiffness and hydrophobicity of the PCL fiber mesh does not provide significant cell attachment and proliferation in cardiac tissue engineering. Many studies have been carried out towards the improvement of PCL characteristics, for example Venugopal et al. proposed a blend of PCL and collagen types I and III [78]. The tensile modulus of the structures was $18 \mathrm{MPa}$ with a tensile strength of 7.79 MPa, appropriate for a blood vessel conduit. Furthermore, the proliferation of coronary artery smooth muscle cells (CASMCs) seeded on PCL/collagen scaffolds has significantly increased.

The combination of PCL with different natural polymers such as collagen, elastin and gelatin has revealed that electrospun $\mathrm{PCL} /$ gelatin scaffolds showed a higher tensile strength when compared to the other hybrid scaffolds according to HeydarkhanHagvall et al. [79]. The effects of pore size on cell attachment and

Table 1

Electrospun scaffolds based on natural polymers in cardiac tissue engineering.

\begin{tabular}{|c|c|c|c|c|c|c|}
\hline Material & Fibers morphology & Cultured cells & $\begin{array}{l}\text { In } \\
\text { vitro }\end{array}$ & In vivo & $\begin{array}{l}\text { Publication } \\
\text { year }\end{array}$ & Ref. \\
\hline Fibrinogen & Random & Rat neonatal cardiac fibroblasts & レ & & 2007 & [66] \\
\hline Silk fibroin/PEO & Random & $\begin{array}{l}\text { Human aortic endothelial cells (hAEC) \& human coronary } \\
\text { artery smooth muscle cells (hCASMC) }\end{array}$ & $\boldsymbol{\nu}$ & & 2008 & [71] \\
\hline Chitosan & Random & Ventricular CMs from neonatal rats, \& coculture with fibroblasts & レ & & 2013 & [68] \\
\hline Fibrinogen/gelatin & Random & CMs & $\boldsymbol{\nu}$ & & 2013 & [72] \\
\hline Albumin & Random \& aligned & Rat neonatal CMS & $\boldsymbol{\nu}$ & & 2014 & [73] \\
\hline Collagen & Random & $\mathrm{H} 9 \mathrm{c} 2$ & $\nu$ & & 2015 & [63] \\
\hline Collagen & Random & CMs, hiPSCs & $\nu$ & $\begin{array}{l}\sim \text { Mouse model } \\
\text { of DCM }\end{array}$ & 2016 & [64] \\
\hline
\end{tabular}


migration was determined by in vitro studies using adiposederived stem cells culture, where cell migration into the scaffold was predominantly seen in the PCL/gelatin hybrid.

In another study, random and aligned $\mathrm{PCL} /$ gelatin composite nanofibrous scaffolds were electrospun to structurally mimic the oriented ECM [80]. Results indicated that PCL/gelatin nanofibrous scaffolds possessed smaller fiber diameters $(239 \pm 37 \mathrm{~nm}$ for random fibers and $269 \pm 33 \mathrm{~nm}$ for aligned fibers), increased hydrophilicity, and lower stiffness compared to electrospun PCL nanofibers. The aligned PCL/gelatin nanofibers showed anisotropic wetting characteristics and mechanical properties, which closely match the requirements of native cardiac anisotropy. Rabbit CMs were cultured on electrospun random and aligned nanofibers to assess the biocompatibility of scaffolds, together with its potential for cell guidance. It was revealed that the aligned PCL/gelatin scaffold greatly promoted cell attachment and alignment because of the biological components and ordered topography of the scaffolds.

Reddy et al. proposed a compound of PCL and an oligomer hydrogel [Bisphenol A ethoxylated dimethacrylate (BPAEDMA)] for the fabrication of electrospun scaffolds [81]. The elastic modulus of PCL/BPAEDMA nanofibrous scaffolds was found to be decreased with the increase of the BPAEDMA weight fraction. Compound scaffolds containing $75 \mathrm{wt} \%$ BPAEDMA oligomer hydrogel exhibited lower modulus (3.55 MPa) and a very low contact angle $\left(25^{\circ}\right)$. BPAEDMA with high degree of ethoxylation resulted to highly flexible elastomeric hydrogels when treated by UV radiation. The contained soft ethylene oxide segments of the blended oligomer provided flexibility and allowed bioadhesion of cells, while the polymerizable methacrylate end groups supplied mechanical strength tunability. In addition, these elements are both non-toxic and non-immunogenic, which are two essential requirements for biocompatible implantable materials. Photopolymerization of this oligomer led to the formation of flexible elastomeric hydrogel films and nanofibers [82]. Rabbit CMs cultured for 10 days on these PCL/BPAEDMA scaffolds, remained viable and expressed cardiac troponin and alpha-actinin proteins for the normal functioning of myocardium, where cell adhesion and proliferation were significantly increased on scaffolds containing 75 wt\% BPAEDMA.

Chen et al. managed to seed murine iPSCs (miPSCs) directly on a 3D PCL nanofibrous scaffold - which was previously coated with a layer of gelatin - and initiated non-directed, spontaneous differentiation using the monolayer method [83]. At day 15 of differentiation, miPSCs differentiated into functional CMs on the 3D PCL nanofibrous scaffold, as evidenced by positive immunostaining of cardiac-specific proteins including cardiac troponin $\mathrm{T}$ (cTnT) and myosin light chain 2a (MLC2a). In addition, flow cytometric analysis of cTnT-positive cells and cardiac-specific gene and protein expression of cTnT and sarcomeric $\alpha$-actinin, demonstrated that the $\mathrm{CM}$ differentiation of miPSCs was more efficient on the 3D PCL nanofibrous scaffold than on normal tissue culture plates .

Furthermore, Fleischer et al. fabricated a 3D spring-like fiber scaffold of PCL for cardiac tissue engineering, in view that coiled fibers have a key role within the natural fibrous matrix of the myocardium, allowing the synchronous contraction and relaxation of cardiac cell bundles with minimal energy loss [84]. The hypothesis was that since in vivo straightening and re-coiling of these fibers allows stretching and contraction of the myocardium in the direction of the CMs, such a scaffold can support the assembly of a functional cardiac tissue capable of generating a strong contraction force (Fig. 3(1)). Rat CMs engineered within 3D thick spring-like

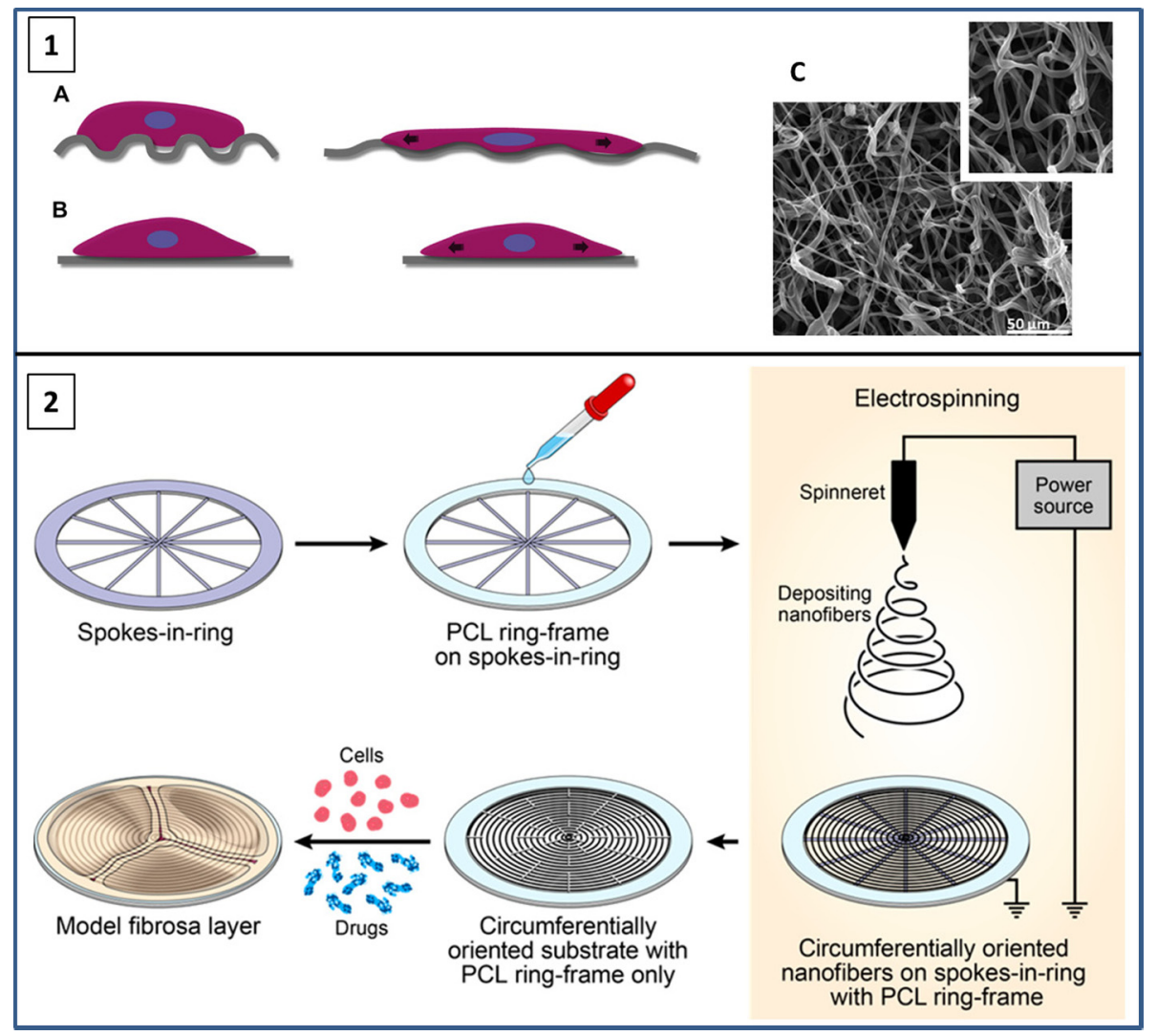

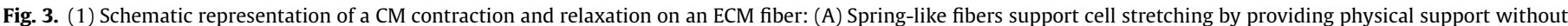

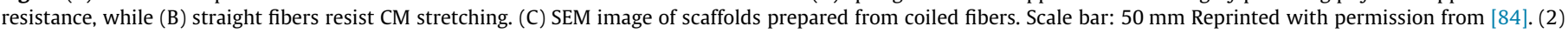
Schematic diagram explaining the fabrication process of a model fibrosa layer. Reprinted with permission from [85]. 
fiber scaffolds formed a functional tissue exhibiting significantly improved function, including stronger contraction force, higher beating rate, and lower excitation threshold, compared to straight fiber scaffolds. These scaffolds, composed of tortuous fibers, had an average pore area of $44,000 \mathrm{~mm}^{2}$, corresponding to a pore diameter of $470 \mathrm{~mm}$ which allowed the penetration of cells and their assembly into bundles of myocytes.

Guex et al. demonstrated that radio-frequency plasma surface functionalized electrospun PCL Fibers provide a suitable matrix for bone-marrow-derived MSCs cardiac implantation. The plasma treatment method characteristics will be reported in Section 4.2.2. The designed cardiac patch, acellular vs. seeded with MSCs, was evaluated in a rodent model of chronic myocardial infarction (MI) and it was revealed that MSC-seeded plasma-coated PCL grafts stabilized cardiac function and attenuated dilatation. Significant relative decreases of $13 \%$ of the ejection fraction (EF) and 15\% of the fractional shortening (FS) were observed in sham treated animals; respective decreases of $20 \%$ and $25 \%$ were measured 4 weeks after acellular patch implantation, whereas a steady function was observed 4 weeks after MSC-patch implantation (relative decreases of $6 \%$ for both $\mathrm{EF}$ and $\mathrm{FS}$ ) [85].

An interesting application of electrospinning was presented by Jana et al. who fabricated an in vitro model of the fibrosa layer of a cardiac aortic valve using PCL [86]. Fibrosa layer is composed mostly of a dense network of type I collagen fibers oriented in circumferential direction. Thus, a morphologically biomimicking and standalone substrate with circumferentially oriented nanofibers was fabricated by electrospinning on an appropriately designed collector (Fig. 3(2)). Cultured valvular interstitial cells (VICs) from porcine aortic valve showed a fibroblast phenotype that is generally observed in a healthy aortic leaflet, and their morphology was close to those in the fibrosa layer of a native aortic leaflet, rendering this approach promising for in vitro studies of valvular dysfunctions.

\subsubsection{Scaffolds based on PLLA, PLGA and their copolymers}

Another category of materials used for cardiac tissue purposes are the polymers poly-(L-lactide) (PLLA), polyglycolide (PGA) and the copolymer poly(lactide-co-glycolide) (PLGA).

In vitro studies of biodegradable non-woven PLGA-based scaffolds using primary $\mathrm{CMs}$ from rats have shown a dose-response effect of the PGA concentration on the degradation rate and the $\mathrm{pH}$ value changes [87]. It was found that CMs had a preference for relatively hydrophobic surfaces such as PLLA. PLLA scaffolds promoted better cell adhesion and mature cytoskeleton structure with well-defined periodic units in the contractile machinery (sarcomeres). Functional studies of CMs on the scaffolds, by optical imaging of electrical activity using voltage-sensitive dyes, substantiated the superior response on PLLA scaffolds compared to PLGA + PLLA and PLGA + PEG-PLA (poly(ethylene glycol)-poly(D,L-lactide) diblock copolymer).

Co-electrospinning of PLGA with two natural proteins - gelatin and a-elastin - led to stable scaffolds in an aqueous environment without crosslinking, which were more elastic than those made of pure elastin fibers [88]. The PLGA-gelatin-elastin scaffold turned into stable fiber-laden hydrogel in an aqueous medium, with suitable mechanical properties which were adjusted by the ratio of the components. Cytocompatibility tests with H9c2 rat cardiac myoblasts revealed that myoblasts grew equally as well or slightly better on the scaffolds than on tissue-culture plastic. Myoblasts reached confluence on the scaffold surfaces while simultaneously growing into the scaffolds.

A 3D culture system based on electrospun PGA was fabricated for the study of cell lines of cardiac stem cells (CSCs) using a ckit antibody from adult rat hearts which has previously being established by the same group [89]. C-kit -positive cardiac cells are well recognized as CSCs and have the potential to differentiate into CMs [90] although some studies have rather suggested a preferential differentiation towards the vascular cell lineage [91]. Composites of collagen-PGA were prepared, that contained different amounts of electrospun PGA nanofibers, where the latter were added as a sheet that formed a layer within the collagen sponge. The sponges were freeze-dried and then dehydrothermally crosslinked. The PGA nanofibers significantly enhanced the compressive strength of the collagen sponge. The attachment and proliferation of CSCs in the 3D culture was enhanced by incubation in a bioreactor perfusion system compared with $3 \mathrm{D}$ static and $2 \mathrm{D}$ (i.e. tissue culture plates) culture systems.

In vitro studies of hiPSCs using aligned PLGA electrospun nanofibers coated on cell culture plates have shown that these cells better approximate normal cardiac tissue compared with those cultured on a flat surface, indicating the desire of an anisotropic environment [92]. In addition, electrospun PLGA-collagen (PLGA$\mathrm{Col})$ scaffolds have been studied as substrates for the differentiation of pluripotent embryonic stem cells (ESCs) isolated from the inner mass of blastocysts. During the culture of embryoid bodies' outgrowth on the scaffolds, and further differentiation of ESCs to $\mathrm{CMs}$, the PLGA-Col nanofibers were found superior than electrospun PLGA nanofibers, as a better interaction and growth of ESC differentiated CMs was observed on the composite scaffolds. PLGA scaffolds were found hydrophobic with a contact angle of $128.11^{\circ}$, whereas PLGA/Col scaffolds showed hydrophilic properties with a contact angle of $48.89^{\circ}$. The hydrophilic PLGA/Col nanofibers might serve as a favourable scaffold compared to PLGA for cardiac treatment [93].

Moreover, a scaffold consisting of a commercial copolymer of LLA with trimethylene carbonate (PLLA-co-TMC) was investigated in comparison to electrospun PLLA. The PLLA-Co-TMC scaffold is a glassy rigid material at room temperature while it is a rubbery soft material at $37^{\circ} \mathrm{C}$. Mechanical characterization results (tensile stress-strain and creep-recovery measurements) showed that at $37^{\circ} \mathrm{C}$ electrospun PLLA-Co-TMC displayed an elastic modulus of around $20 \mathrm{MPa}$ and the ability to completely recover up to $10 \%$ of deformation. Cell culture experiments have shown that this copolymer scaffold promotes CMs proliferation and preserves cell morphology, without impeding expression of sarcomeric $\alpha$ actinin marker [94].

Another combination of PCL and PGA of various compositions showed that with the increase of the concentration of PGA in spinning blend solution, the average diameter of nanofibers, hydrophilicity, and mechanical properties of the nanofibrous scaffolds increased. An in vitro degradation study of PCL:PGA nanofibers conducted in phosphate buffered saline confirmed that increasing the amount of PGA provides faster degradation rate in blended nanofibers. Cell attachment and spreading of cardiac progenitor cells (isolated from newborn rat heart) seeded on the scaffolds indicated that among electrospun nanofibrous scaffolds, the most appropriate candidate for myocardial tissue engineering scaffolds is PCL:PGA (65:35) [95].

A composite of electrospun poly(1,8-octanediol-co-citrate) (POC) and PLLA-Co-PCL (PLCL) was proposed by Prabhakaran et al., where its mechanical properties can be adjusted by tuning the amount of POC [96].The composite scaffold with POC/PLCL ratio of 40:60 [POC/PLCL4060] was found to have a tensile strength of $1.04 \pm 0.11 \mathrm{MPa}$ and Young's modulus of $0.51 \pm 0.10 \mathrm{MPa}$, comparable to the native cardiac tissue. The proliferation of cardiac rat myoblast cells ( $\mathrm{H} 9 \mathrm{c} 2$ ) on the electrospun POC/PLCL scaffolds increased from days 2 to 8 , with the increasing concentration of POC in the composite. The morphology and cytoskeletal observation of the cells also demonstrated the biocompatibility of the POC containing scaffolds, indicating that electrospun POC/PLCL4060 nanofibers can be promising elastomeric substrates. 
An electrospun composite of PLA with poly(ethylene glycol) dimethacrylate (PEGdma) was developed aiming to mimic the structure and mechanical properties of native valve leaflets [97]. As PLA is highly hydrophobic, PEGdma, which can be photochemically crosslinked, was used to additionally stabilize the fibrous scaffold. Culture of VICs and valvular endothelial cells (VECs) on the scaffold under physiological conditions in a bioreactor resulted in a construct with performance like a native leaflet. Atomic force microscopy (AFM) revealed that spongiosa stiffness was much lower compared to the fibrosa and ventricularis. Taking into consideration investigations into human fetal heart valve development that identified collagen type I and versican as key structural proteins, they were introduced to the scaffold in order to demonstrate the ability of this hybrid valve biofunctionalization.

Recently, heterogenous nanofibrous scaffolds consisted of PLCL and the hydrophilic poly(ethyl oxazoline) (PEOz) at specific ratio have been demonstrated to mimic the native collagen fiber heterogeneity of the left ventricular cardiac tissue [98]. These scaffolds contain fibers with two different diameters of $100-150 \mathrm{~nm}$ and $\sim 500 \mathrm{~nm}$, obtained by electrospinning the aforementioned blend. H9c2 cells culture has shown improved cell compatibility along with the expression of cardiac marker proteins in the case of PLCL/PEOz at ratio 70:30.

\subsubsection{Polyurethane-based scaffolds}

Polyurethane (PU) based electrospun materials are another category often used for the construction of heart valves. For example, primary cardiac ventricular cells were grown on electrospun, biodegradable PU with either aligned or unaligned microfibers and supported high-density cultures and cell subpopulations, remained intact over two weeks in culture [99]. PU cultures contained electrically-coupled CMs with connexin-43 localized to points of cell-cell contact. Multi-cellular organization correlated with microfiber orientation and aligned materials yielded highly oriented CM groupings. Atrial natriuretic peptide (ANP), a molecular marker that shows decreasing expression during ventricular cell maturation, was significantly lower in cultures grown on PU scaffolds than in those grown on tissue culture polystyrene. Cells grown on aligned PU had significantly lower steady state levels of ANP and constitutively released less ANP over time indicating that scaffold-imposed cell organization resulted in a shift in cell phenotype to a more mature state, suggesting that the physical organization of microfibers in PU scaffolds impacts both multicellular architecture and cardiac cell phenotype in vitro. PU mesh scaffolds were utilized for the generation and seeding of ESCderived CMs as well. The cells were elongated in shape, morphology typical of cultured ESC-derived CMs, sarcomeric myosin and connexin 43 expression was evident, and contracting cells were observed [100]. In addition, the same research group studied the effect of scaffold architecture and co-culture with mouse embryonic fibroblasts (MEFs) on the differentiated phenotype of murine ESC-derived CMs (mESCDCs) [101]. Both aligned and random fibrous PU scaffolds were fabricated by electrospinning, and it was found that the aligned scaffolds led to the anisotropic organization of rodshaped cells, improved sarcomere organization, and increased mESCDC aspect ratio when compared to cells on the random-fibrous scaffolds. Moreover, pre-seeding the scaffolds with MEFs improved mESCDC sarcomere formation compared to mESCDCs cultured alone.

Biodegradable thermoplastic elastomers are attractive for application in cardiovascular tissue construct development due to their amenability to a wide range of physical property tuning. For example, electrospun poly (ester urethane) ureas (PEUU) were developed by Stankus et al. which demonstrated the integration of living cells into electrospun PEUU scaffolds [102]. Vascular SMCs isolated from rat aorta were electrosprayed simultaneously with the electrospinning of PEUU using a rotating mandrel collector, resulting in SMC microintegrated PEUU constructs with high cells density achieved in a short period of time and with high anisotropy. A comprehensive study of the same group of electrospun PEUU under variable conditions which modelled the effects of fiber orientation on the macro-mechanical properties of the scaffold, has shown that the high velocity electrospun scaffolds exhibited highly anisotropic mechanical properties closely resembling the native pulmonary heart valve leaflet [103]. Aiming to mimic the mechanical properties of a native pulmonary valve in both flexural and equi-biaxial tensile response, Amaroso et al. studied the effect of microstructural features, that are important on the flexural behaviour of electrospun scaffolds, by introducing secondary electrospun fibers to the PEUU with simultaneous electrospinning [104]. It was noticed that mixed fiber constructs with higher modulus had higher bending and tensile moduli when secondary fibers were stiffer (PCL) than PEUU, whereas sacrificial fibers (PEO) within scaffolds were found to decrease overall construct modulus. Hobson et al. presented another approach of developing curvilinear fiber alignment in electrospun scaffolds by varying the geometry of the collecting mandrel in order to mimic the native semi-lunar heart valves [105]. PEUU was electrospun onto rotating conical mandrels of varying angles to produce fibrous scaffolds where the angle of fiber alignment varied linearly over scaffold length. By matching the radius of the conical mandrel to the radius of curvature for the native pulmonary valve, the electrospun constructs exhibited a curvilinear fiber structure similar to the native leaflet (Fig. 4).

Moreover, using knitted conventional textiles made of cotton or polyester yarns as templates of electrospinning collectors, Senel Ayaz et al. created anisotropic 3D scaffolds from polycarbonateurethane (PCU, Bionate ${ }^{\circledR}$ ), which exhibited mechanical properties close to native in comparison to PLGA ones [106]. In vitro studies (initially with $\mathrm{H} 9 \mathrm{c} 2$ cells) with neonatal rat CMs demonstrated the functionality in terms of physiologic contractility of the electrospun anisotropic polyester-templated Bionate scaffolds.

A composite based on PU and ethyl cellulose (PU/EC) was fabricated featuring uniform fibrous nanostructures and 3D porous networks which proved to be biocompatible for retention and proliferation of cardiac myoblast H9c2 cells [107]. The high mechanical strength of the PU/EC scaffolds enables the processing

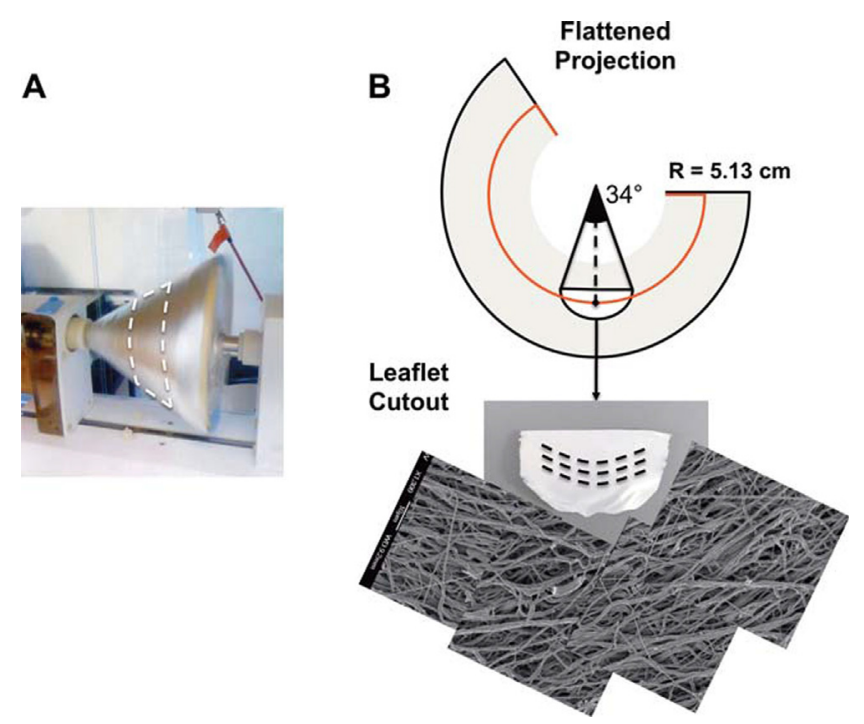

Fig. 4. (A) Picture of the conical mandrel during production of curvilinear electrospun sheets. (B) Scheme of the flattened, conical electrospun sheet (top) and image of the excised leaflet with SEM images. Reprinted with permission from [105]. 
and handling of an ultrathin patch. Their elastomeric characteristics revealed the compatibility between the patch and contractile tissues. Furthermore, anisotropic PU/EC scaffolds with aligned nanofibers were successfully fabricated, exhibiting higher mechanical strength and essential characteristics for the survival and function of cardiac cells with native anisotropy.

\subsubsection{Poly(glycerol sebacate)-based scaffolds}

Poly(glycerol sebacate) (PGS) has emerged in the last decade, as a very attractive polymer for soft tissue engineering [108]. Indeed, PGS is a thermoset elastomer synthesized from nontoxic monomers, glycerol and sebacic acid, which can be degraded and completely resorbed in vivo.

A PGS/gelatin core-shell electrospun composite reported for the co-culture of MSCs and CMs [109]. In this composite PGS used as a core polymer to impart the mechanical properties and gelatin as a shell material to achieve favourable cell adhesion and proliferation. The cardiogenic differentiation of MSCs was confirmed by employing MSC-specific marker protein CD 105 and cardiac-specific marker protein actinin. Ravichandran et al. supported that the co-culture of MSCs and CMs with a suitable elastomeric biomaterial combination such as PGS/gelatin has synergistic effects and are more effective than MSCs or CMs alone.

Whereas, in another study, PGS and gelatin were blended before electrospinning resulting to the fabrication of scaffolds with welldefined anisotropy that can mimic the left ventricular myocardium architecture [110]. From the in vitro studies using neonatal rat cardiac fibroblast cells (CFs) and CMs, it was found that aligned fibrous scaffold, consisting of $33 \mathrm{wt} \%$ PGS, induced optimal synchronous contractions of CMs while significantly enhanced cellular alignment.

Kenar et al. used a polyester blend consisted of PGS, poly(3hydroxybutyrate-co-3-hydroxyvalerate) (PHBV) and P(L-D,L)LA and for the fabrication of aligned electrospun mats [111]. The basic 3D construct design involved two biodegradable macroporous tubes, to allow transport of growth media to the cells within the construct, and cell-seeded, aligned fiber mats wrapped around them. The electrospun parallel fibers proved to be effective for the alignment of MSCs from human umbilical cord matrix (Wharton's Jelly) after their culture on them, where the cells were able to retract the mat. The $3 \mathrm{D}$ construct was cultured in a microbioreactor by perfusing the growth media transiently through the macroporous tubing for two weeks and enhanced cell viability, uniform cell distribution and alignment due to nutrient provision from inside the 3D structure were confirmed.

Non-linearly elastic biomaterials were successfully fabricated from a chemically cross-linked elastomeric PGS and PLLA using the core/shell electrospinning technique [112]. The electrospun materials, containing a PGS core and PLLA shell, demonstrated Jshaped stress-strain curves and displayed ultimate tensile strength, rupture elongation, and stiffness constants comparable to muscle tissue properties. In vitro evaluations also showed that PGS/PLLA fibrous biomaterials possess excellent biocompatibility, capable of supporting human ESC-derived CMs over several weeks in culture.

An electrospun fibrous blend of PGS and poly(butylene succinate-butylene dilinoleate) (PBS-DLA) of different compositions was examined for its suitability for heart patches [113]. The addition of PBS-DLA to PGS resulted in an increase of the average fiber diameter, whereas increasing the amount of PBS-DLA the elastic modulus was increased as well as the hydrophobicity of the blended scaffolds. Initial toxicity studies with $\mathrm{C} 2 \mathrm{C} 12$ myoblast cells up to $72 \mathrm{~h}$ confirmed the nontoxic behaviour of the blends. CMs culture results contradicted those of the C2C12 cells, where the PBS-DLA 70/30 scaffolds showed the lowest cell viability. Authors claimed that $\mathrm{CMs}$ seem to be more sensitive to the matrix stiffness, showing better attachment and maturation on the softer matrix. Comparing to the controls used in the study (gelatin- and fibronectin-coated glass coverslips), CMs attach and spread much faster on PGS/PBS-DLA fiber blends than on gelatin and the same as fibronectin.

\subsubsection{Scaffolds based on other polymeric materials}

Recently Castellano et al. presented an extensive study on the ability for cardiac repair of various electrospun scaffolds including poly(3-hydroxybutyrate) (PHB), PCL, silk, PLLA, polyamide (PA) which were compared to a non-crosslinked collagen membrane that was used as control [114]. In vitro studies using mouse cardiac HL-1 cell line, cardiac fibroblasts and MSCs from dental pulp showed that PHB and PCL polymers allowed the greatest adhesion/growth of cells. In vivo studies with acellular patches on the epicardial surface of healthy rats have shown that only collagen and PHB patches were progressively degraded. Implantation on infarcted rat heart indicated that only PHB induced significant angiogenesis. Nevertheless, in vivo studies with cell-seeded patches are required in order to prove the superior properties of PHB electrospun scaffolds.

Scaffolds made of lipase-catalyzed poly( $\omega$-pentadecalactone) (PPDL) have been reported by Focarete et al. [115]. The main advantage of PPDL is its slow resorbability which is essential in tissue-engineering applications that require long healing times. The biocompatibility of PPDL scaffolds was evaluated using embryonic rat cardiac H9c2 cells. It was demonstrated that H9c2 cells retain their native, mesenchymal spindle shaped, sheet-like morphology and cover the scaffold surface with a confluent cell monolayer, which is promising for the usage of PPDL scaffolds for cardiac tissue engineering.

Polydioxanone (PDO) electrospun bioabsorbable valved patches were studied for restoring the right ventricular outflow tract (RVOT) [116]. The scaffold seeded with MSCs was implanted in the right ventricular outflow tract (RVOT) of growing lambs and the function, histological changes and potential of growth, and tissue regeneration of PDO were investigated. Autologous bloodderived MSCs were labeled with quantum dots and seeded on PDO electrospun valved patches. Those were implanted into the RVOT of 6 growing lambs followed up until 8 months. Tissueengineered RVOT were neither stenotic nor aneurismal and displayed a growth potential, with less fibrosis, less calcifications and no thrombus compared with control polytetrafluoroethylene (PTFE)-pericardial patches. The PDO scaffold was completely degraded and replaced by a viable, three-layered, endothelialized tissue and an extracellular matrix with elastic fibers similar to that of native tissue. Detection of quantum dots at 1 month suggested that at least some of the cells were-derived from the grafted cells. The PDO electrospun tissue-engineered valved transannular patch appears to be a promising device in restoring a living RVOT and could ultimately lead to applications in the treatment of congenital RVOT diseases. The same group further compared electrospun scaffolds of PU, poly(3-hydroxybutyrate-co-3-hydroxyvalerate-co-4hydroxyvalerate (PHBVV) and PDO, using two biofunctionalization techniques: adipose-derived stem cells or arginine-glycineaspartate (RGD) peptide in a rat model of partial inferior vena cava replacement [117]. In vitro studies using adipose-derived stem cells and in vivo results revealed the superior properties of PDO, while the two functionalization methods yielded similar outcomes.

Moreover, electrospun scaffolds obtained by mixing poly[1,8octanediol-co-(citricacid)-co-(sebacicacid)] (POCS) and fibrinogen in various ratios have been utilized for cardiac tissue engineering [118]. These composites have shown flexibility and biodegradability. Culture with human CMs revealed that the scaffold POCS/fibrinogen with ratio $1: 1$ is the optimum with excellent cell growth and no toxicity and has a potential for cardiac tissue regeneration. 
Table 2

Electrospun scaffolds based on synthetic polymeric materials in cardiac tissue engineering.

\begin{tabular}{|c|c|c|c|c|c|c|}
\hline Material & $\begin{array}{l}\text { Fibers } \\
\text { morphology }\end{array}$ & Cultured cells & In vitro & In vivo & $\begin{array}{l}\text { Publication } \\
\text { year }\end{array}$ & Ref. \\
\hline PCL & Random & CMs & $\boldsymbol{}$ & & 2004 & [74] \\
\hline PCL & Random & CMs & $\boldsymbol{}$ & & 2005 & [75] \\
\hline $\mathrm{PCL}+$ collagen I \& III & Random & Coronary artery smooth muscle cells (CASMCs) & & & 2005 & [78] \\
\hline $\begin{array}{l}\text { PLLA, PLGA + PLLA, } \\
\text { PLGA + PEG-PLA }\end{array}$ & Random & Rat primary CMs & $\boldsymbol{\nu}$ & & 2005 & [87] \\
\hline PLGA-gelatin-elastin & Random & H9c2 & $\boldsymbol{\nu}$ & & 2006 & {$[88]$} \\
\hline $\begin{array}{l}\text { PEUU-cosprayed } \\
\text { SMCs }\end{array}$ & Random & Vascular SMCs isolated from rat aorta & $\boldsymbol{}$ & & 2006 & [102] \\
\hline PEUU & Random & & $\begin{array}{l}\text { Pulmonary } \\
\text { heart valve } \\
\text { leaflet }\end{array}$ & & 2006 & {$[103]$} \\
\hline $\begin{array}{l}\text { PCL/gelatin } \\
\text { PCL/collagen } \\
\text { PCL/elastin }\end{array}$ & Random & Adipose-derived stem cells & $\boldsymbol{\nu}$ & & 2008 & [79] \\
\hline PU & $\begin{array}{l}\text { Random \& } \\
\text { aligned }\end{array}$ & Rat primary ventricular CMs & レ & & 2008 & [99] \\
\hline PU & Random & ESC-derived CMs & $\boldsymbol{}$ & & 2008 & {$[100]$} \\
\hline Collagen-PGA & Random & CSCs & $\boldsymbol{\nu}$ & & 2010 & [89] \\
\hline PPDL & Random & $\mathrm{H} 9 \mathrm{c} 2$ & $\nu$ & & 2010 & [115] \\
\hline PDO & $\begin{array}{l}\text { Rectangular } \\
\text { mandrel, } \\
\text { random }\end{array}$ & Autologous blood-derived MSCs & $\boldsymbol{\nu}$ & $\boldsymbol{\sim}$ RVOT of growing lambs & 2010 & [116] \\
\hline PCL/gelatin & $\begin{array}{l}\text { Random \& } \\
\text { aligned }\end{array}$ & Rabbit CMs & レ & & 2011 & {$[80]$} \\
\hline PLLA-Co-TMC & Random & CMs & $\boldsymbol{}$ & & 2011 & [94] \\
\hline PGS/gelatin & $\begin{array}{l}\text { Core-shell, } \\
\text { random }\end{array}$ & Coculture MSCs and CMs & レ & & 2011 & [109] \\
\hline $\begin{array}{l}\text { Blend(PHBV), P(L-D,L) } \\
\text { LA, PGS }\end{array}$ & Aligned & Wharton's Jelly MSCs & レ & & 2011 & [111] \\
\hline POC/PLCL & Random & H9c2 & レ & & 2012 & [96] \\
\hline PU & $\begin{array}{l}\text { Random \& } \\
\text { aligned }\end{array}$ & $\begin{array}{l}\text { Mouse embryonic fibroblasts on the differentiated } \\
\text { phenotype of murine ESC-derived CMs }\end{array}$ & $\boldsymbol{\nu}$ & & 2012 & [101] \\
\hline PEUU with PCL, PEO & Random & & $\begin{array}{l}\text { Pulmonary } \\
\text { heart valve } \\
\text { leaflet }\end{array}$ & & 2012 & [104] \\
\hline PGS/gelatin & Aligned & Neonatal rat cardiac fibroblast cells \& CMs & レ & & 2013 & {$[110]$} \\
\hline PGS-PLLA & $\begin{array}{l}\text { Core-shell, } \\
\text { random }\end{array}$ & Human ESC-derived CMs & レ & & 2013 & [112] \\
\hline 3D spring like PCL & Random & Rat CMs & レ & & 2013 & {$[84]$} \\
\hline PLGA-collagen & Random & Pluripotent ESCs differentiation to CMs & $\boldsymbol{V}$ & & 2014 & [93] \\
\hline PCL-PGA & Random & $\begin{array}{l}\text { Cardiac progenitor cells (isolated from newborn } \\
\text { rat heart) }\end{array}$ & レ & & 2014 & {$[95]$} \\
\hline PLA-PEGdma & Random & VICs and valvular endothelial cells (VECs) & レ & & 2014 & [97] \\
\hline $\begin{array}{l}\text { PCL-treated with } \\
\text { plasma }\end{array}$ & Random & Bone-marrow-derived MSCs & $\boldsymbol{\nu}$ & $\begin{array}{l}\sim \text { Rodent model of } \\
\text { chronic MI }\end{array}$ & 2014 & {$[85]$} \\
\hline PCL/BPAEDMA & Random & Rabbit CMs & レ & & 2014 & [81] \\
\hline $\begin{array}{l}\text { Plasma treated PHB, } \\
\text { PCL, silk, PLLA, PA }\end{array}$ & Random & $\begin{array}{l}\text { Mouse cardiac HL-1 cell line, cardiac fibroblasts } \\
\text { and MSCs from dental pulp }\end{array}$ & レ & $\begin{array}{l}\sim \text { Acellular patches-rat } \\
\text { model of MI }\end{array}$ & 2014 & {$[114]$} \\
\hline PCU, Bionate ${ }^{\circledR} /$ PLGA & Random & $\begin{array}{l}\text { H9c2 on PLGA \& Bionate, and neonatal rat CMs on } \\
\text { Bionate }\end{array}$ & $\boldsymbol{}$ & & 2014 & [106] \\
\hline Cell electrospinning & $\begin{array}{l}\text { Core-shell, } \\
\text { random }\end{array}$ & Primary neonatal CMs & レ & & 2014 & [120] \\
\hline $\begin{array}{l}\text { PCL coated with } \\
\text { gelatin }\end{array}$ & Random & Murine iPSCs & レ & & 2015 & [83] \\
\hline PCL & Random & $\begin{array}{l}\text { Valvular interstitial cells (VICs) from porcine aortic } \\
\text { valve - fibrosa layer }\end{array}$ & レ & & 2015 & {$[86]$} \\
\hline PLGA & Aligned & hipscs & $\boldsymbol{}$ & & 2015 & [92] \\
\hline $\mathrm{PLCL} / \mathrm{PEO} z$ & Random & $\mathrm{H} 9 \mathrm{c} 2$ & レ & & 2015 & [98] \\
\hline PEUU & Random & & $\begin{array}{l}\text { Pulmonary } \\
\text { heart valve } \\
\text { leaflet }\end{array}$ & & 2015 & [105] \\
\hline $\mathrm{PU} / \mathrm{EC}$ & $\begin{array}{l}\text { Random \& } \\
\text { aligned }\end{array}$ & $\mathrm{H} 9 \mathrm{c} 2$ & $\checkmark$ & & 2015 & [107] \\
\hline PGS, PBS-DLA & Random & C2C12 myoblast cells & $\boldsymbol{\nu}$ & & 2015 & [113] \\
\hline PDO, PU, PHBVV & Random & Adipose-derived stem cells & レ & $\begin{array}{l}\boldsymbol{V} \text { Rat of partial inferior } \\
\text { vena cava replacement }\end{array}$ & 2015 & [117] \\
\hline POCS/fibrinogen & Random & Human CMs & レ & & 2015 & [118] \\
\hline
\end{tabular}

Another interesting approach is the so-called "cell electrospinning" introduced ten years ago by Jayasinghe and co-workers, which demonstrated the ability to directly electrospin living cells for the development of living scaffolds [119]. This technique is based on the use of a coaxial needle arrangement where a concentrated living biosuspension flows through the inner needle and a polymeric medium (poly(dimethyl siloxane)) with high viscosity and low electrical conductivity flows through the outer needle. Their research revealed that the high applied voltage did not directly have an adverse effect on the cells as the current in 
these experiments was kept in very low values (nanoamperes). Recently, this group demonstrated the ability to directly handle primary neonatal CMs as concentrated cellular suspensions for the formation of living cardiac fibers and scaffolds using cell electrospinning [120]. The in vitro studies indicated that the cell electrospinning does not alter CMs viability where the function of the latter is maintained.

Table 2 summarizes the scaffolds characteristics, in terms of synthetic polymers based materials, fibers morphology, in vitro/ in vivo studies.

From the aforementioned, it becomes apparent that there is flexibility in the use of a variety of polymeric materials, both natural and synthetic, in any combination which can be electrospun and can lead to functional scaffolds for cardiac tissue engineering. Using blended polymers in the initial solution prior to electrospinning or utilizing coaxial electrospinning for the formation of core/ shell nanofibers is an attractive option for balancing the weaknesses of one polymer with the strengths of another. There is a huge amount of work focusing on the struggle of adjusting the mechanical properties of the scaffolds. It is unsafe at the moment to conclude which of the reported scaffolds meets better the criteria of an ideal cardiac scaffold as different results obtained by using different type of cardiac cells. Nevertheless, it becomes evident that elastomeric materials are preferential in a mechanically dynamic environment, such as the cardiovascular tissue. The results obtained by using synthetic scaffolds were superior. Last in terms of the structure, when random and aligned fibers were compared for the myocardium tissue engineering, the latter had a clear precedence. This is an open field, and the research is expected to grow during the coming years in the field of heart cell therapy. Nevertheless, in furtherance of achieving a functional scaffold, more consistent studies should be carried using the same type of cardiac cells, preferentially human derived stem cells, in synergy with cell-seeding conditions using appropriate bioreactors.

\section{Methods for improving scaffolds functionalities}

It is self-evident that the material properties of the electrospun nanofibers play a huge role in the interactions between the scaffolds and cardiac cells. In terms of viability, the most important properties are those of the surface and not the bulk of the material. As in many other applications, a specific material might be suitable for the creation of the scaffold, but its surface properties may not be suitable for cardiac cell growth. Instead of using other materials, it is quite common to modify the polymer of interest and to induce the desired properties on the surface or the bulk. Using several techniques, the microenvironment of the scaffold at the interface between the cells and the polymer, where they adhere and interact with the scaffold itself, can be improved. In some other cases, a particular modification might be employed to improve a desired functionality of the electrospun nanofiber surfaces, which corresponds to the desired change of the interaction of the material with the cardiac cells. The classification of the modification methods presented herein includes co-electrospinning by combining biological elements and conductive materials, and surface post treatment with wet (chemical) and dry (plasma) techniques (fig. 5). In many cases, a combination of these methods has been reported for the achievement of the optimum scaffold.

\subsection{Co-electrospinning with additives (pre-treatment)}

\subsubsection{Co-electrospinning with biological materials}

One very common method used is the incorporation of biological materials in the initial polymeric material, and subsequent electrospinning of the mixture (co-electrospinning). This way, a polymer that lacks a specific biological functionality can be improved. Usually, this pertains to the survival and the normal behaviour of cardiac cells that are cultured in the scaffolds. These biomaterials seem to efficiently improve adhesion, viability, and biocompatibility of the scaffolds while other properties like differentiation towards a specific type of cells appears to be affected in specific cases.

Yu et al. incorporated short peptides previously covalently conjugated to poly-t-lysine. Two adhesive peptides $\mathrm{N}$-acetylGRGDSPGYG (RGD) and N-acetyl-GYIGSRGYG (YIGSR) - both deriving from laminin - were mixed with PLGA to electrospin, and compared to laminin -coated PLGA scaffolds [121]. In vitro studies using rat CMs indicated that the cells cultured on the YIGSR incorporated and the laminin-coated aligned scaffolds showed

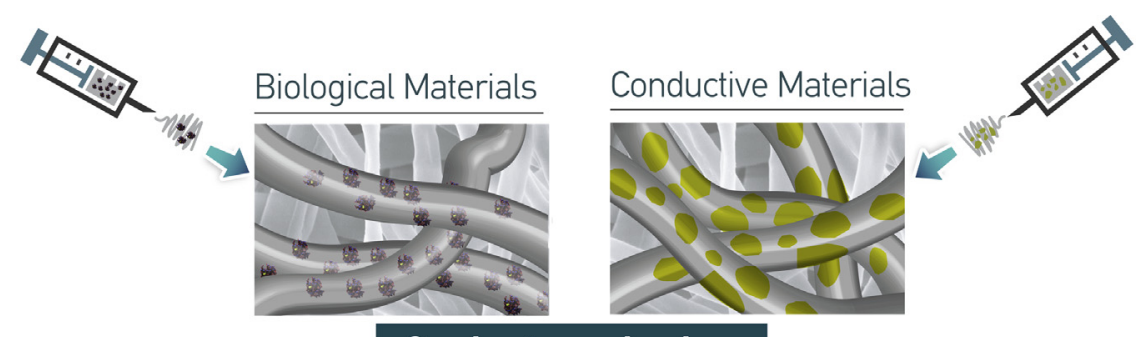

Coelectrospinning

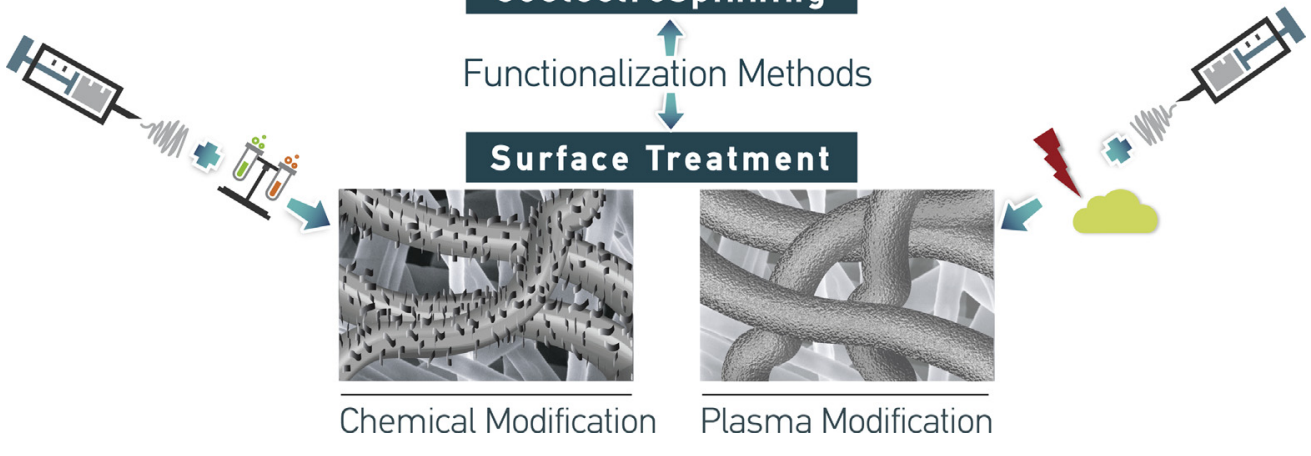

Fig. 5. Classification of the functionalization methods of electrospun scaffolds in cardiac tissue engineering. 
physiological-like morphology, while the overall superior behaviour corresponded to the YIGSR-PLGA.

Spadaccio et al. proposed the functionalization of PLLA electrospun fibers with granulocyte colony-stimulating factor (G-CSF) [122]. G-CSF has shown to have a direct effect on CMs, by restraining apoptotic behaviour and remodeling in a failing heart as well as by protecting from ventricular arrhythmias. This is achieved by the up-regulation of connexin 43 (Cx43). By adding G-CSF, the orientation of stem cell differentiation can be controlled, and important local and systemic effects can be wielded to adjust the myocardial microenvironment. Also by using G-CSF, the mechanical properties of the scaffold produced by electrospinning mimics more the properties of the natural connective tissue.

Bhaarathy et al. have incorporated 2 different components in the initial polymer to improve different functionalities [123]. Their study uses PLCL, silk fibroin (SF) and Aloe Vera (AV) to create a scaffold via electrospinning so as to use it as an implantable material. The study showed that the myocardial microenvironment was influenced positively in terms of cellular adhesion, morphology, proliferation and protein expression for neonatal rat CMs. The nanofibers of PLCL/SF/AV showed elasticity and mechanical properties similar to those of the myocardium, also giving a positive environment in terms of contractility. The presence of Aloe Vera also adds up to the functionality of the scaffold and its potential use as a cardiac patch, since it induces anti-allergic and antiinflammatory effects to the electrospun scaffold.

Simón-Yarza et al. used a polymer blend containing PLGA and six-armed star-shaped poly(ethylene oxide-stat-propylene oxide) with isocyanate end groups (NCO-sP(EO-stat-PO) with $80 \%$ EO content, to encapsulate the cardioactive growth factor Neuregulin-1 (Nrg) [124]. The evaluation of the electrospun scaffold with the encapsulated biomaterial was performed in a rat model of myocardial ischemia, regarding biocompatibility, adherence, and degradation. The study outcomes showed a promising therapeutic strategy for the repair of myocardial tissue, since the constructed synthetic scaffold yielded results consistent with constructive tissue remodeling.

In addition to the above, one of the most sophisticated electrospun scaffolds was proposed by Tian et al. which developed PLCL electrospun scaffolds by emulsion electrospinning, a technique for the formation of core-shell nanofibers (Fig. 6) [125]. Aiming to develop a sustained release scaffold which could be a promising substrate for cardiovascular tissue regeneration, Tian et al. encapsulated VEGF, which is an indispensable bioactive growth factor for cardiovascular regeneration, with either dextran or bovine serum albumin (BSA) into the core of PLCL nanofibers by emulsion electrospinning. Dextran and BSA acted as the protective agents in order to maintain the bio-activity of the encapsulated VEGF in the electrospun PLCL. In vitro release study of VEGF using phosphate buffered saline revealed that the PLCL-VEGF-dextran nanofibers are capable of delivering the growth factor in a more sustained manner. The same group used core/shell nanofibrous scaffolds of PGS and fibrinogen where they injected VEGF and MSCs in an in vivo porcine model with infarcted myocardium [126]. The in vivo studies demonstrated that most of the transplanted MSCs within the scaffolds expressed the cardiac marker proteins and prevented negative ventricular remodeling of the myocardium by offering structural support to the left ventricle wall.

Similarly, introduction of VEGF in electrospun mats using the water-oil emulsion method was utilized for synergistically inducing angiogenesis and cardiomyogenesis in an acute myocardial infarction model of rats [127]. Epicardial co-implantation of VEGF and CSCs using a PLLA electrospun mat enabled the sustained release of VEGF, leading to improved cell retention, neovascularization, engraftment rate and enhanced global cardiac function.

Overall this method gives the advantage of incorporating biological materials in the bulk of the nanofiber and thus introducing all the desired biological functionalities. This way the new composite material will have better biocompatibility. The absence of the necessary adhesive sequences that are essential for cell adhesion and cell viability [128] can be drastically improved. Combining the properties of the initial polymer and its suitability for electrospinning, a new advanced material is aimed to be created. On the other hand, this approach shows similar disadvantages as the use of biological materials does. The initial mechanical properties are becoming inadequate with the increase of the addition of the biological component [129]. Additionally, there is always the risk of rapid degradation in the electrospinning process of the biological materials in a way that the fibers loose the function and activity of the incorporated biological materials [130]. Also, the material itself should be homogenized to avoid variability of biological properties in the nanofibers. All this tuning needed for this approach to be effective also increases the cost.

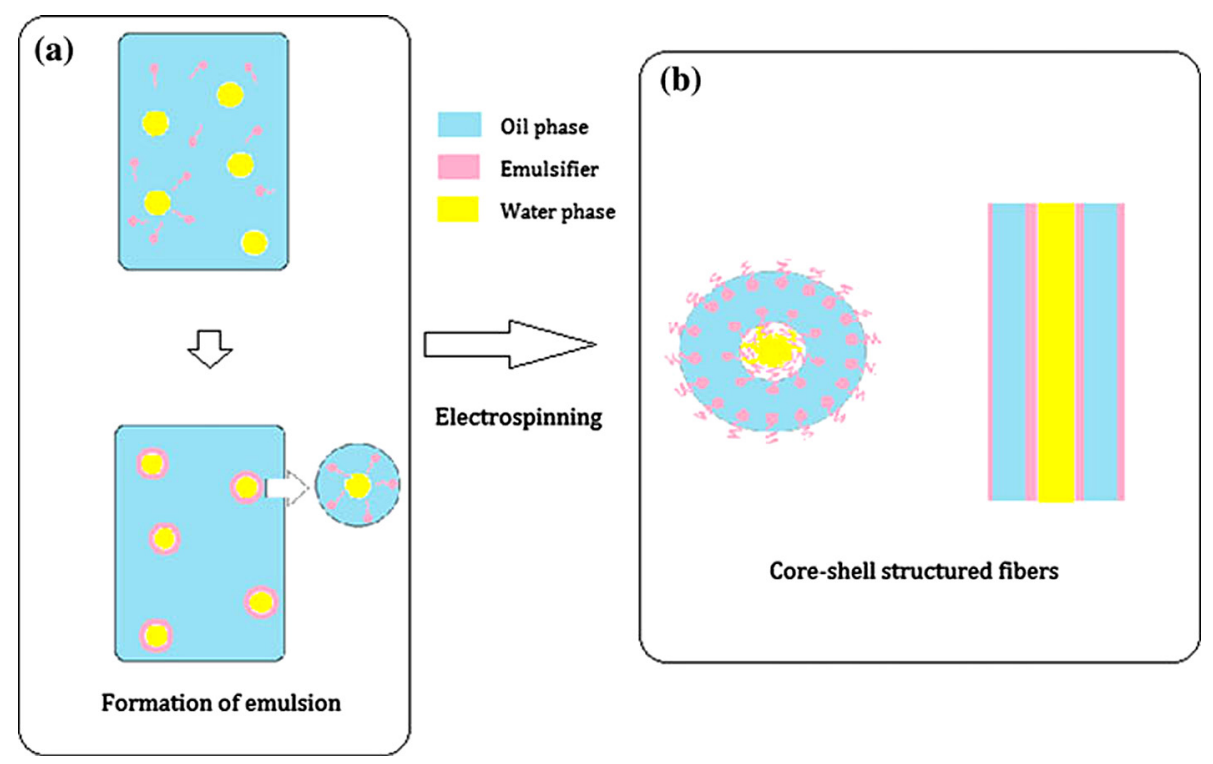

Fig. 6. Schematic representation of emulsion electrospinning for producing core-shell nanofibers. Reprinted with permission from [125]. 
This method although seemingly simplistic becomes complex due to the complexity of the biological materials by nature, and to their non-compatibility with the method of electrospinning. Potentially a biomaterial synthesized with the use of biological elements in a way that it can show increased mechanical properties could be a better alternative than this approach.

\subsubsection{Co-electrospinning with conductive materials}

The ventricle in the human body shows a remarkable contractility. The mechanism underlying this ability of contraction is driven by the synchronous contraction of CMs. In order for the CMs to contract successfully, an electrical signal drives the contraction and is supported by the mechanical properties of the human myocardium. Thus, we can claim that one of the most important issues for cardiac tissue engineering is the improvement in scaffold conductivity (appropriate conduction velocity). Controlling conductivity in electrospun scaffolds will help to promote the functionalization and maturation of regenerated tissues. The materials that are traditionally used for the utilization of the electrospun scaffolds do not combine appropriate mechanical and electrical properties. This is the reason behind the inability of engineered tissues to keep up with the pace of contraction of the native myocardium. As a result, when a scaffold is implanted in the heart, it is common that arrhythmias are observed [131]. Scaffolds with the desired conductivity could sense the native electrical signals successfully and prevent arrhythmias. This way, they could promote CMs rhythmic contraction and subsequently direct the differentiation of cardiac tissues in vitro, since rhythmic contraction can promote cell alignment and electrical coupling of cultured cardiac cells [44].

Another strategy used in order to enhance the functionalities of the electrospun scaffold is the addition and dispersion of functional agents in the initial solvent of the polymer to create a composite so that after electrospinning, the added functionalities will affect the behaviour of cells. These could be nanoparticles or functional polymers which are added to the initial solution and co-electrospun with the initial polymer, similar as in the previous case of adding biomaterials. Therefore, to improve conduction velocity of the scaffold to an appropriate value as mentioned before, conductive and biocompatible additives can be used for co-electrospinning.

Carbon nanotubes in general, have been used as additives in several cases to improve the conductivity of polymers, since they show excellent conductive properties and descent biocompatibility $[132,133]$. Based on these studies Crowder et al. proposed the addition of multiwall carbon nanotubes (MWCNTs) in PCL [134]. This way the conductivity was up to $35 \mathrm{mS} / \mathrm{cm}$, depending on the composition. Human MSCs that were cultured on the scaffolds created with this composite material containing MWCNTs showed an elongated morphology which is similar to that of CMs while there was a strong colocalization between mouse antihuman myosin heavy chain $(\alpha-\mathrm{MYH})$ and F-actin cytoskeleton, thereby suggesting early cardiac differentiation. Kharazila et al. also incorporated CNTs in PGS/gelatin electrospun nanofibers improving the electrical conductivity along with the mechanical properties of the fibers without affecting negatively any biological properties. The resulting scaffolds showed enhanced beating properties for the cultured cardiac tissue [135].

Gold has been used extensively for cell studies due to its biocompatibility and high stability. The incorporation of gold nanoparticles (AuNPs) is another conductive substance that is used to improve conductivity and mechanical properties. Fleischer et al. added AuNPs to PCL and reported that this addition of AuNPs affected the morphology of the cardiac tissues [136]. The morphology of the cells was elongated and aligned, which mimics the morphology inside the myocardium. Another work proposes the electrospinning of incorporated AuNPs to Bis(trimethylsilyl)ac- etamide (BSA)/Poly(vinyl alcohol) (PVA) mixture [137]. The scaffold created was used for culturing MSCs and the differentiation was reported. The cells showed the characteristic morphology of cardiac cells, as well as cardiac protein expression for actinin, Troponin-T and $\mathrm{Cx} 43$, leading to conclude that AuNP loadedcaffolds provoked the functional differentiation of MSCs. The same group used a PCL/Silk Fibroin/Vitamin B12/Aloe Vera/AuNP mixture to create scaffolds and direct the differentiation of MSCs into cardiac lineage [138]. The MSCs were co-cultured with cardiac cells on the fabricated scaffolds. AuNPs and Vitamin B12 provided the functionalities in terms of chemistry and physical properties towards the enhancement of the MSCs proliferation and differentiation into cardiogenesis, a fact that was measured by the phenotype and the cardiac marker expression in the differentiated MSCs. Jung et al. also combined the incorporation of AuNPs as well as peptides with polymethylglutarimide (PMGI) to create electrospun scaffolds, which potentiated cardio-myocyte differentiation of human ESCs and iPSCs [139].

One also common method to improve conductivity is the incorporation of conductive biocompatible polymers in the same way as described previously (co-electrospinning). Polyaniline (PANI) and polypyrrole (PPy) are the two most used conductive polymers for co-electrospinning [140-144]. By using this approach, an electrically active scaffold can be created, which will coordinate the synchronous beating of cultured CMs in the scaffold. These materials (PANI and PPy) are compatible and amenable to the electrospinning technology, while their conductivity can be manipulated by the change of the percentage of the conductive polymer in the initial mixture. For example Hsiao et al. fabricated nanofibers by co-electrospinning of PANI with PLGA (Fig. 7) [140]. The main difficulty here lays in the fact that their chemical composition can be affected by this process, which may change their biological and mechanical properties.

In total, this method incorporates materials that can induce specific functionalities to the bulk of the material and focuses mostly on the properties side of the material used for electrospinning. The mechanical properties can very easily be tuned into the desired ones, as well as advanced functionalities like conductivity can be achieved. This approach has the advantage of excellent compatibility and suitability of the process itself. The science used to promote the desired functionalities is well established and in most of the cases the materials used are of lower cost than the equivalent biological ones described in Section 4.1.1. For all the above the chemical and mechanical properties of the produced nanofibers can be highly reproducible [145].

On the other hand in most of the cases, a further step is needed since biocompatibility of the produced nanofibers is low. Also the fact that most of the polymers are hydrophobic creates an additional difficulty in culturing cells on the fibers, especially for the more hydrophobic ones. Additionally, toxicity [146-148] and biodegradation is a big concern and is problematic when nanoparticles are used [130]. Although this method can provide advanced functionalities on the electrospun nanofibers that are produced, it lacks essential functionalities that have to do with mimicking the ECM. Further additional steps are needed to improve cell adhesion on the surface. As stated in Section 4.1.1, unless there is a biocompatible, non-toxic and non-degrading material with these specific functionalities, it will be highly unlikely that this approach by itself can produce the desired electrospun nanofibers to create a scaffold for in vivo application.

\subsection{Surface modification of electrospun nanofibers (post-treatment)}

\subsubsection{Post treatment by chemical modification}

One of the most important factors on the fabrication of functional materials for biological applications is the modification of 


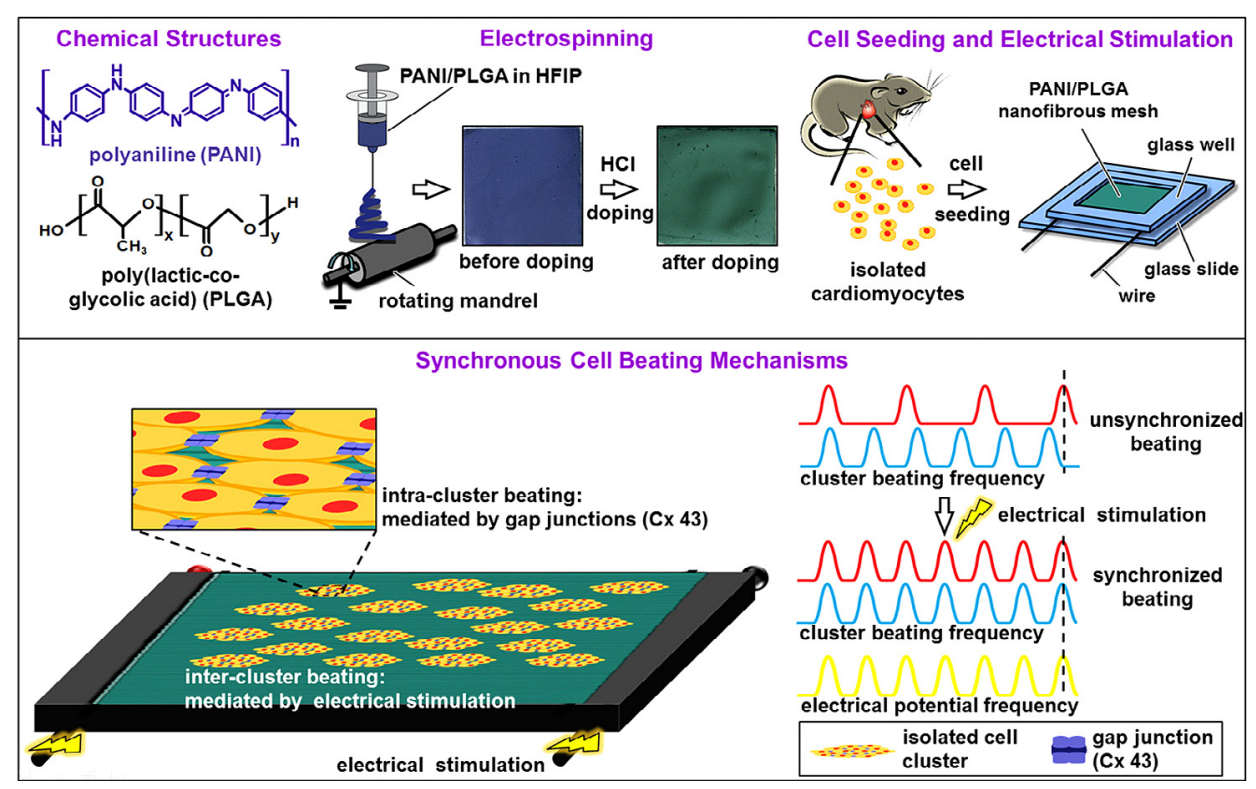

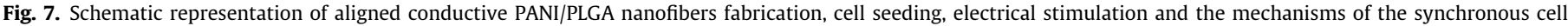
beatings. Reprinted with permission from [140].

the surface chemistry. This can be achieved either by introducing functional groups on the surface of the material or by modifying the existing functional groups [149].

Hsiao et al. used hydrochloric acid $(\mathrm{HCl})$ to induce positive charges on the surface of co-electrospun PANI and PLGA fibers (Fig. 7) [140]. This way they achieved to dope the surface of the fibers with positive charges and thus attract the negatively charged adhesive proteins fibronectin and laminin improving CM attachment on the scaffolds.

Shevach et al. [150] proposed the deposition of 2-14 nm AuNPs on the surface of co-electrospun PCL-gelatin fibers (Fig. 8). The AuNP coated scaffolds promoted the alignment and the elongation of cardiac tissue compared to the non-coated ones. Also, the ratio of CMs to fibroblasts was maintained in the culture, promoting an impressive cardiac sarcomeric actinin expression. The contractility of the AuNP coated scaffolds was also enhanced compared to the non-coated one, exhibiting higher contraction rate and amplitude.

Another approach used for improving specific functionalities of the electrospun scaffolds is polymerization on the surface of the fibers. Jin et al. polymerized pyrrole on the surface of PLLA scaffold, creating discrete hollow polypyrrole (PPy) fibers with deep $(100 \mu \mathrm{m})$ interconnected pores [151]. This structure allowed the entry of CMs and showed excellent results for proliferation and morphology of the cultured cells. In another study, dopamine was also polymerized on the surface of PLCL [152]. Polydopamine allowed gelatin immobilization on the surface, without affecting the mechanical properties of the electrospun nanofibers. Additionally polydopamine and gelatin synergistically affected CM adhesion and proliferation.

A post-treatment with a biologically active substance is also a very common method for the improvement of the biological properties of the electrospun fibers. The scaffolds are incubated in solutions containing the biological substance, which coats the surface of the fibers. Fibronectin is the most widely used biological substance for cardiac cells and has been coated on chitosan [68], PCL [153] [84], PLA [154] and PU [99]. Collagen type-I was also used on P(L-D,L)LA [111] and laminin on PLGA [121]. In all cases, the cells show improved attachment, proliferation, and viability, while in some cases the desired shape of CMs is achieved.

$\mathrm{NaOH}$ is commonly used to chemically modify the surface of electrospun scaffolds in tissue engineering. It has been used both in PLLA and PCL scaffolds to make their surfaces superhydrophilic by introducing $-\mathrm{OH}$ on the polymer surface. The cultured cells showed favourable morphology and adhesion $[155,156]$. The only study reported so far to use $\mathrm{NaOH}$ for cardiac tissue engineering,

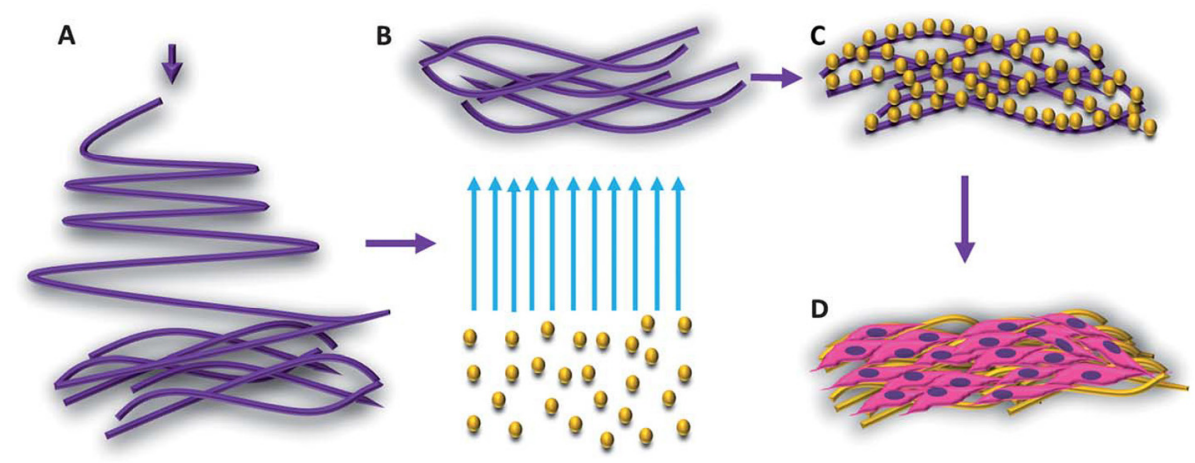

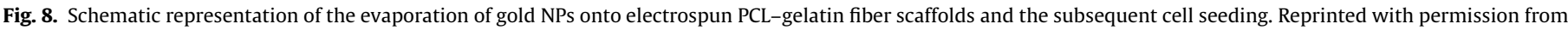
[150]. 
uses it to etch biofunctionalized PLGA, without apparently taking advantage of the change in chemistry of the polymer surface [121].

Summarizing, this method induces chemical and/or biological changes on the surface of the electrospun nanofibers to modify and improve the surface properties of the initial material used for electrospinning. The main advantage of this approach lies in the fact that the bulk of the nanofiber is not affected and thus does not change properties. This way, a material with desired mechanical properties can be used for the process of electrospinning (it can also be a co-electrospun advanced material like the aforementioned in Section 4.1), which subsequently is modified (bio)chemically to improve the biocompatibility, cell adhesion and cell viability in a uniform and homogeneous fashion. The main disadvantage would be that some of the processes may degrade rapidly, while in other cases the chemical modification can decompose the material if it affects it at a bigger depth [129]. In addition, although the chemistry of the surface can be modulated to mimic the ECM of the myocardium, there is also the nanomorphology of the nanofibers that in most of the cases is not following the same approach. Chemistry is controlled, but structuring of the surface is either not changed or not done in a controlled fashion [157] to induce desired structural changes on the surface of the electrospun nanofibers. Although this method is simple, direct, and cost effective, if coupled with a more sophisticated method it can significantly increase production cost [158].

All in all this approach, if combined with the methods described in Section 4.1, can be a very promising technique towards which more research should be directed. Research should be focusing on understanding the mechanisms responsible for the attachment cells on the modified surfaces, i.e. covalent bonding or sorption (e.g. physisorption, chemisorption, adsorption), so that the nature of the changes that these biochemical processes induce is fully controlled and explained. There is a lot of research on the chemical modification and its potential shows that more focus will be put on this technique in the near future.

\subsubsection{Post treatment by plasma modification}

Plasma treatment is one of the most extensive methodologies that are used to improve specific properties and functionalities of materials. Biological properties can be controlled and modified via the intrinsic ability of plasma to modify surface properties of polymers, like surface chemistry, $\zeta$-potential, wettability, electrical conductivity and morphology [159-162].

Guex et al. [85] used a radio-frequency plasma source to modify the surface of PCL fibers. An oxygen functional hydrocarbon coating was deposited on the PCL fibers using a mixture of ethene $\left(\mathrm{C}_{2} \mathrm{H}_{4}\right)$, carbon dioxide $\left(\mathrm{CO}_{2}\right)$ and argon ( $\left.\mathrm{Ar}\right)$ for $15 \mathrm{~min}$. XPS analysis confirmed the formation of an oxygen functional hydrocarbon layer, on the surface of the PCL fibers by plasma polymerization. These plasma coated PCL fibers were tested in vivo in a rat model and had shown good mechanical integrity (Fig. 9).
Bhaarathy et al. use air plasma treatment to improve the wettability of the surface of PLCL, SF and AV blend biocomposite nanofibrous scaffolds [123]. Plasma treated samples become more hydrophilic, allowing the attachment of cardiac cells as well as the desired proliferation and shape. Likewise Castellano et al. utilized $\mathrm{N}_{2}$ plasma for the introduction of polar groups onto the surface of PHB, PCL, PLLA, silk, PA electrospun scaffolds prior to cell culture [114].

Plasma surface modification as a method for improving the surface properties is quite unique as it can induce many different changes on the surface simultaneously or selectively one by one. Another advantage is the fact that it can change selectively areas of interest and not the whole area of the scaffold comparing to all the other methods, giving this method the option to create multifunctional scaffolds using one tool. Plasma in principle creates chemical modification by introducing energetic ions on the surface and subsequently changes conductivity and surface energy [161]. As in Section 4.2.1 it can be used as a different kind of chemical modification method for biomolecule immobilization and this way improving cell adhesion, proliferation, and viability [163]. It can be used as a deposition tool for a variety of coatings, or it can increase the surface of the nanofibers by graphitization [161]. Due to its nature, plasma also creates nanostructuring on surfaces either due to etching or due to deposition $[159,160,162,164,165]$, so it can also be a tool for the reconstruction of the desired micro/nanoenvironment that mimics the cardiac ECM. Finally, an additional advantage is the UV irradiation that plasma creates by default and is a benefit on the decontamination of surfaces. The disadvantages of this method are mostly due to the fact of the anisotropic nature of plasma. Because of this, the parts that are "shaded" on the vertical movement of the ions fail to functionalize. Also, the use of vacuum systems increases the complexity and the cost of the process comparing to a simple chemical modification and the use of a single chemical.

Concluding, plasma surface modification can achieve multiple functionalities using a single method, which is a unique advantage comparing to all the aforementioned methods. Although this method is not widely used for electrospun nanofibers due to its disadvantages, the recent advances in atmospheric pressure plasma systems, combined with the very recent science of microplasmas (plasma sources the size of microns), can provide a new tool for achieving the desired morphology and functionalities of the electrospun nanofiber scaffold. There is very little research done so far in this area, but this method shows great potential. The science of plasma surface modification for tissue engineering has been thoroughly investigated in the last 10 years for polymeric films, and this in combination with recent technologies of plasmas, it can provide the desired solutions towards the functionalization of electrospun scaffolds for cardiac tissue engineering.

Table 3 summarizes the scaffolds details in the modification methods described above. The references that are included in
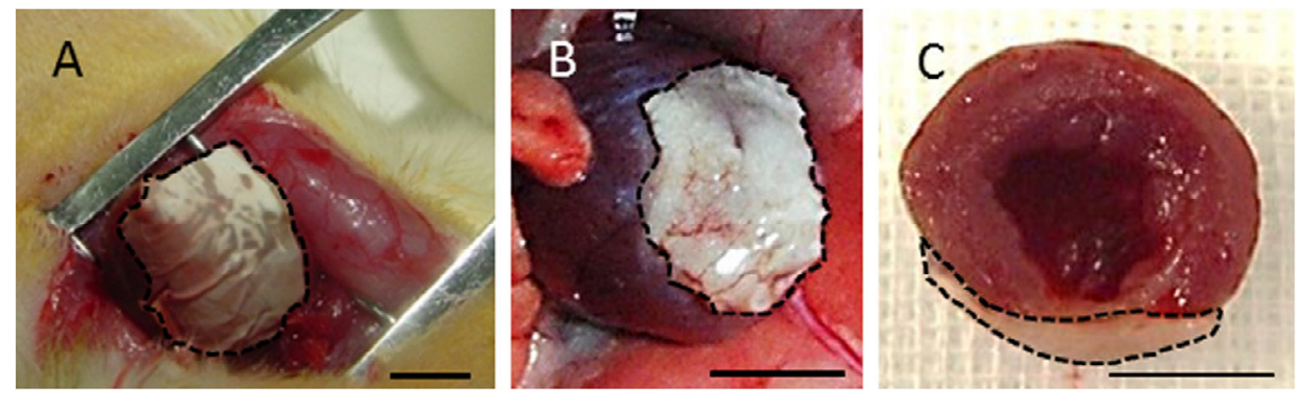

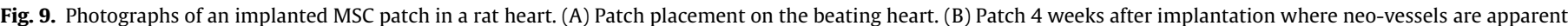

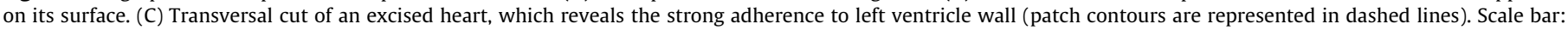
$5 \mathrm{~mm}$. Reprinted with permission from [85]. 
Table 3

Modification of electrospun scaffolds in cardiac tissue engineering.

\begin{tabular}{|c|c|c|c|c|c|c|c|}
\hline Material & $\begin{array}{l}\text { Fibers } \\
\text { morphology }\end{array}$ & Modification & Cultured cells & $\begin{array}{l}\text { In } \\
\text { vitro }\end{array}$ & In vivo & $\begin{array}{l}\text { Publication } \\
\text { year }\end{array}$ & Ref. \\
\hline PANI blend & Random & Gelatin & H9c2 & $\boldsymbol{r}$ & & 2006 & [143] \\
\hline PLA & Random & Fibronectin & Neonatal rat CMs & レ & & 2010 & [154] \\
\hline PANI & Random & $\begin{array}{l}\text { Poly-L-lysine dendrimers } \\
\text { (HPLys) }\end{array}$ & Neonatal rat CMs & $\nu$ & & 2010 & [144] \\
\hline PCL & Random & PANI & Human MSCs & レ & & 2011 & [141] \\
\hline $\begin{array}{l}\text { PCL + Polypyrrole } \\
\text { (PPy) }\end{array}$ & Random & Gelatin & Rabbit CMs & $\boldsymbol{r}$ & & 2011 & [142] \\
\hline PLCL & Random & Polydopamine + gelatin & Neonatal rat CMs & $\boldsymbol{\nu}$ & & 2011 & [152] \\
\hline PLLA & Random & G-CSF & CMs & レ & & 2011 & [122] \\
\hline PLCL & Random & $\begin{array}{l}\text { VEGF + BSA or dextran } \\
\text { emulsion }\end{array}$ & Human bone derived MSCs & $\boldsymbol{\nu}$ & & 2012 & [125] \\
\hline PMGI & Random & Peptides + AuNPs & Human ESCs \& iPSCs & レ & & 2012 & [139] \\
\hline Fluffy PPy scaffold & Random & $\begin{array}{l}\text { Polymerized from fluffy } \\
\text { PLLA }\end{array}$ & Neonatal rat CMs & レ & & 2012 & [151] \\
\hline PCL & Aligned & MWCNTs + gelatin coating & Human MSCs & $\boldsymbol{\nu}$ & & 2013 & [134] \\
\hline PCL & Random & Sputtered AuNPs & Neonatal rat $\mathrm{CMs}$ & レ & & 2013 & [150] \\
\hline PLGA & Aligned & $\mathrm{PANI}+\mathrm{HCl}$ & Neonatal rat CMs & レ & & 2013 & {$[140]$} \\
\hline PLGA & $\begin{array}{l}\text { Random \& } \\
\text { aligned }\end{array}$ & $\begin{array}{l}2 \text { adhesive peptides RGD, } \\
\text { YIGSR, laminin-coating }\end{array}$ & Primary CMs from neonatal rats & $\boldsymbol{\nu}$ & & 2014 & [121] \\
\hline PLCL & Random & $\begin{array}{l}\text { Silk fibroin + Aloe Vera + Air } \\
\text { plasma }\end{array}$ & CMs from neonatal rats & $\boldsymbol{r}$ & & 2014 & [123] \\
\hline PGS:gelatin & Aligned & CNTs & Neonatal rat CMs & $\boldsymbol{\nu}$ & & 2014 & {$[135]$} \\
\hline PCL & $\begin{array}{l}\text { Coiled } \\
\text { fibers }\end{array}$ & AuNPs & Neonatal rat CMs & レ & & 2014 & [136] \\
\hline PVA/BSA & Random & AuNPs & Human MSCs & $\boldsymbol{\nu}$ & & 2014 & [137] \\
\hline PGS/fibrinogen & Random & VEGF + MSCs & $\begin{array}{l}\text { Human bone derived MSCs differentiated } \\
\text { into cardiac \& endothelial cells }\end{array}$ & $\nu$ & $\begin{array}{l}\boldsymbol{\nu} \text { Porcine model of } \\
\text { myocardial infarction }\end{array}$ & 2015 & [126] \\
\hline PLLA & Random & VEGF + CSCs & CSCs & $\boldsymbol{r}$ & $\begin{array}{l}レ \text { Rat model of } \\
\text { myocardial Infarction }\end{array}$ & 2015 & [127] \\
\hline PCL & Random & Fibronectin & $\begin{array}{l}\text { Neonatal rat cardiac cells } \\
\text { (CM's + fibroblasts) }\end{array}$ & レ & & 2015 & [153] \\
\hline PCL & Random & SF/AV/Vit12/AuNPs & Rabbit CMs + human MSCs & $\boldsymbol{\nu}$ & & 2015 & [138] \\
\hline $\begin{array}{l}\text { PLGA/NCO-sP } \\
\quad(\text { EO-stat-PO) }\end{array}$ & Random & +Neuregulin-1 & & $\boldsymbol{r}$ & $\begin{array}{l}レ \text { Rat model of } \\
\text { myocardial ischemia }\end{array}$ & 2015 & [124] \\
\hline
\end{tabular}

Tables 1 and 2, but described in the current section as well regarding their modification are not included in Table 3 once more.

\section{Conclusions}

An overview of the polymeric electrospun scaffolds used so far for cardiac tissue engineering purposes has been reported in this review. Authors' opinion is that there is not a unique material that can be considered as a panacea for cardiac therapy. Most of the scaffolds made by synthetic polymers need post treatment in order to obtain sufficient cell attachment. Electrospun scaffolds can be modified using several methods; out of them the most commonly used are the co-electrospinning of materials that can improve desired functionalities of the initial polymer, and the deposition of biologically functional coatings. Both of them are quite simple and non-specialist methods, but can prove to be quite complex in some cases in terms of chemical stability, since they can induce undesired changes in the composition of the initial polymer.

In addition, although there are several studies showing the effect of changes in the nanoscale in other types of cells and tissues, for the case of cardiac cells only a few recent studies examine the effect of the nanoscale on the viability, attachment, shape and proliferation of cardiac cells (all of them not on 3D scaffolds). This effect of nanoscale induced changes, can tune protein expression and direct the behaviour of cardiac cells, as is the case in other types of cells. One could comment and predict that useful insights on the mechanisms of the nano-environment of the myocardium could be given with the aforementioned studies, and this could lead to better control on the fabricated scaffolds, this time in the nanoscale.
Regarding to surface post-treatment, plasma modification shows a lot of potential and there is a huge new interest in the use of plasma to attach, modify and direct cells on electrospun nanofibers. The unique ability of plasmas to modify the local chemistry and the surface characteristics simultaneously gives them an advantage over other surface modification methods. Comparing to the case of using solution chemistry to modify the surface of an electrospun nanofiber, plasma provides a lot more control in the amount of chemical species used as well as a fully controlled environment for the sample in most of the cases. Additionally, the ability to deposit materials with plasmas and also etch using the same equipment could be used to create nanotextured surfaces by "knitting" selectively specific areas of the surface, leading to fully controlled micron or nano scale regions with different functionalities. For these reasons plasma was extensively studied the last few years in terms of tissue engineering for several types of cells, but still, there are only a few studies for cardiac cells.

Though the complexity of cardiac tissue is much bigger than many other types of cells, it is very clear that there is a lot of room for the employment of the techniques that are used in the modification of scaffolds for the culturing of other type of cells to cardiac cells. Thus, the following years there will be a lot of development in this area. Generally speaking from the studies published so far, it is indicated that composite scaffolds, by combining natural and synthetic polymers, are more promising candidates. Their principal advantage is that they can synergistically combine the beneficial characteristics of each individual component to form a material with superior mechanical/elastic and electrical properties together with the essential presence of natural ECM protein adhesion ligands to the cells. 
From the above, it is evident that the material of choice is tightly related to the target application:

- Is an implant to transfer cardiac cells to a part of heart required e.g. left ventricle and then removed? In this case, a bioresorbable polymer is the best choice. However, the possibility of using a natural polymer that has been modified in order to enhance its mechanical properties that in the end it will not degrade or at least degrade slightly is an attractive option as this material will not cause any toxicity and inflammation and it will be connected smoothly with the ECM. At this point, it is worth noting that the crosslinking method is of paramount importance in the case of natural electrospun polymers, as it can affect the 3D structure of the scaffold. Special attention should be taken in order not to induce cytotoxicity, as it has been observed with glutaraldehyde.

- Is a polymeric material that replaces a part of heart, such as a valve, required? Then a biocompatible but not biodegradable, neither bioresorbable material can be considered as the ideal choice.

As an epilogue, from the aforementioned scientific findings, it is observed that the vast majority of the studies concern in vitro results, since only a limited number of published articles present in vivo results (see Tables 1-3). Despite the variety of accepted biomaterials for clinical applications and successful in vitro studies, just only a few studies describe the effective implantation of cardiovascular tissue engineered scaffolds into small animals, and even less using large animals. In vivo studies should focus more on the usage of large animals that simulates better the human heart and more precisely the human heart rate, even though the higher cost is a hindrance.

In either way, it is a fact that the flurry of experimental papers on cardiac scaffolds sharply contrasts with their so far scarce clinical applications, primarily limited to the use of collagen and fibrin. This is an issue that postulates the concern of the scientists in the field, in order to progress in the final target of the implantation of the fabricated electrospun scaffolds in the heart. There are different reasons for this discrepancy: the delayed recognition that delivery tools are key factors of the successful outcome of any cell-based intervention and the subsequent underuse of the scaffolds designed as cell vehicles; the lack of precise understanding of how a given cell type responds to the microenvironmental physical and chemical cues provided by a given material, which may have prevented to fully benefit from effective cell-material interactions. The main regulatory constraints include the availability of the selected scaffold material for human use (including its unrestricted supply, the full traceability of all its components and a detailed description of their sourcing), the documentation of its biocompatibility (assessed by specific tests to probe cytotoxicity, mutagenicity, the extent of the inflammatory and immune responses), the characterization of its degradation kinetics and biodistribution patterns and the maintenance of the key material properties following a clinically-usable mode of sterilization and storage. It is also mandatory that the scaffold can be manufactured according to a robust, scalable and reproducible quality-controlled process. When the scaffold is intended to be used as a vehicle for cells, cell-material interactions also need to be characterized.

Electrospinning thus appears as an attractive method might help addressing some of these obstacles. In particular it allows, by leveraging the various adjustable settings, to fine-tune the 3D architecture of the scaffold and thus to optimize the patterning of cells (those seeded or embedded in the material as well as those from the host) and/or bioactive ligands in a controlled and reproducible fashion which should be helpful for translating the material into a clinically-targeted "product". Alternatively, in an era where the paracrine effects of the cells are considered their primary mechanism of action, leading to think that they might be successfully replaced by their secretome, the precise control over the nanofibrillar scaffold network could optimize its functionalization by biologics with regard to their retention and release kinetics. Electrospinning could also contribute to expanding the indications of cardiac scaffolds by allowing the versatile fabrication of cellmaterial composites usable as epicardial patches intended to be deposited onto the epicardium during a surgical procedure. Finally, some of the features of the electrospinning technique, primarily scalability, consistency, and reproducibility, might facilitate both industrial production and compliance with regulatory requirements.

\section{Acknowledgements}

This work was supported by the French National Research Agency (ANR-12-RPIB-0015, ANR-15-CE08-0010), the LabEx REVIVE (ANR-10-LABX-73), the Fondation de France (FDF/201400047970), the Fondantion de l'Avenir (AP-RMA-2015-036), the LeDucq Foundation (SHAPEHEART network), and the Association Française contre les Myopathies. MK acknowledges funding through the Beatriu de Pinós program (BP-DGR-2013), supported by the Secretary for Universities and Research of the Ministry of Economy and Knowledge of the Government of Catalonia and the Cofund programme of the Marie Curie Actions of the $7^{\text {th }} R \& D$ Framework Programme of the European Union. DK and MK would like to acknowledge the help of Mr Marcos Markou for his artistic contribution in figures of this work.

\section{References}

[1] R. Lozano, M. Naghavi, K. Foreman, et al., Global and regional mortality from 235 causes of death for 20 age groups in 1990 and 2010: a systematic analysis for the Global Burden of Disease Study 2010, Lancet 380 (2012) 2095-2128.

[2] G.W. Reed, J.E. Rossi, C.P. Cannon, Acute myocardial infarction, Lancet (2016), http://dx.doi.org/10.1016/S0140-6736(16)30677-8.

[3] K. Albouaini, M. Egred, A. Rao, A. Alahmar, D.J. Wright, Cardiac resynchronisation therapy: evidence based benefits and patient selection, Eur. J. Intern. Med. 19 (2008) 165-172.

[4] J.J.V. McMurray, M. Packer, A.S. Desai, J. Gong, M.P. Lefkowitz, A.R. Rizkala, J.L. Rouleau, V.C. Shi, S.D. Solomon, K. Swedberg, M.R. Zile, Angiotensin-neprilysin inhibition versus enalapril in heart failure, N. Engl. J. Med. 371 (2014) 9931004 .

[5] J.-S. Silvestre, P. Menasché, The evolution of the stem cell theory for heart failure, EBioMed. 2 (2015) 1871-1879.

[6] J. Dow, B.Z. Simkhovich, L. Kedes, R.A. Kloner, Washout of transplanted cells from the heart: a potential new hurdle for cell transplantation therapy, Cardiovasc. Res. 67 (2005) 301-307.

[7] H. Zhang, P. Song, Y. Tang, X. ling Zhang, S. hua Zhao, Y. jie Wei, S. shou Hu, Injection of bone marrow mesenchymal stem cells in the borderline area of infarcted myocardium: heart status and cell distribution, J. Thorac. Cardiovasc. Surg. 134 (2007).

[8] W. Hudson, M.C. Collins, D. deFreitas, Y.S. Sun, B. Muller-Borer, A.P. Kypson, Beating and arrested intramyocardial injections are associated with significant mechanical loss: implications for cardiac cell transplantation, J. Surg. Res. 142 (2007) 263-267.

[9] F.N. Smets, Y. Chen, L.-J. Wang, H.E. Soriano, Loss of cell anchorage triggers apoptosis (anoikis) in primary mouse hepatocytes, Mol. Genet. Metab. 75 (2002) 344-352.

[10] P.V. Kochupura, E.U. Azeloglu, D.J. Kelly, S.V. Doronin, S.F. Badylak, I.B. Krukenkamp, I.S. Cohen, G.R. Gaudette, Tissue-engineered myocardial patch derived from extracellular matrix provides regional mechanical function, Circulation 112 (2005).

[11] W.-H. Zimmermann, I. Melnychenko, G. Wasmeier, M. Didié, H. Naito, U. Nixdorff, A. Hess, L. Budinsky, K. Brune, B. Michaelis, S. Dhein, A. Schwoerer, H. Ehmke, T. Eschenhagen, Engineered heart tissue grafts improve systolic and diastolic function in infarcted rat hearts, Nat. Med. 12 (2006) 452-458.

[12] K.L. Christman, H.H. Fok, R.E. Sievers, Q. Fang, R.J. Lee, Fibrin glue alone and skeletal myoblasts in a fibrin scaffold preserve cardiac function after myocardial infarction, Tissue Eng. 10 (2004) 403-409.

[13] T. Kofidis, J.L. de Bruin, G. Hoyt, Y. Ho, M. Tanaka, T. Yamane, D.R. Lebl, R.-J. Swijnenburg, C.-P. Chang, T. Quertermous, R.C. Robbins, Myocardial restoration with embryonic stem cell bioartificial tissue transplantation, J. Hear. Lung Transplant. 24 (2005) 737-744. 
[14] V. Chekanov, M. Akthar, G. Tchekanov, G. Dangas, M.Z. Shehzad, F. Tio, M. Adamian, A. Colombo, G. Roubin, M.B. Leon, J.W. Moses, N.N. Kipshidze, Transplantation of autologous endothelial cells induces angiogenesis, Pacing Clin. Electrophysiol. 26 (2003) 496-499.

[15] Y. Miyahara, N. Nagaya, M. Kataoka, B. Yanagawa, K. Tanaka, H. Hao, K. Ishino, H. Ishida, T. Shimizu, K. Kangawa, S. Sano, T. Okano, S. Kitamura, H. Mori, Monolayered mesenchymal stem cells repair scarred myocardium after myocardial infarction, Nat. Med. 12 (2006) 459-465.

[16] A. Mizutani, A. Kikuchi, M. Yamato, H. Kanazawa, T. Okano, Preparation of thermoresponsive polymer brush surfaces and their interaction with cells, Biomaterials 29 (2008) 2073-2081.

[17] M. Yamato, Y. Akiyama, J. Kobayashi, J. Yang, A. Kikuchi, T. Okano, Temperature-responsive cell culture surfaces for regenerative medicine with cell sheet engineering, Prog. Polym. Sci. 32 (2007) 1123-1133.

[18] M. Kitsara, M. Chatzichristidi, D. Niakoula, D. Goustouridis, K. Beltsios, P. Argitis, I. Raptis, Layer-by-layer UV micromachining methodology of epoxy resist embedded microchannels, Microelectron. Eng. 83 (2006) 1298-1301.

[19] M. Kitsara, C.E. Nwankire, L. Walsh, G. Hughes, M. Somers, D. Kurzbuch, X. Zhang, G.G. Donohoe, R. O'Kennedy, J. Ducrée, Spin coating of hydrophilic polymeric films for enhanced centrifugal flow control by serial siphoning, Microfluid. Nanofluid. 16 (2014) 691-699.

[20] P.X. Ma, Scaffolds for tissue fabrication, Mater. Today 7 (2004) 30-40.

[21] M. Kitsara, J. Ducrée, Integration of functional materials and surface modification for polymeric microfluidic systems, J. Micromech. Microeng. 23 (2013) 33001.

[22] C.H. Lee, Y.C. Lim, D.F. Farson, H.M. Powell, J.J. Lannutti, Vascular wall engineering via femtosecond laser ablation: scaffolds with self-containing smooth muscle cell populations, Ann. Biomed. Eng. 39 (2011) 3031-3041.

[23] G.-H. Wu, S. Hsu, Review: polymeric-based 3D printing for tissue engineering, J. Med. Biol. Eng. 35 (2015) 285-292.

[24] J.J. Song, H.C. Ott, Organ engineering based on decellularized matrix scaffolds, Trends Mol. Med. 17 (2011) 424-432.

[25] R.L. Dahlin, F.K. Kasper, A.G. Mikos, Polymeric nanofibers in tissue engineering, Tissue Eng. Part B Rev. 17 (2011) 349-364.

[26] T. Lu, Y. Li, T. Chen, Techniques for fabrication and construction of threedimensional scaffolds for tissue engineering, Int. J. Nanomed. 8 (2013) 337.

[27] M. Boffito, S. Sartori, G. Ciardelli, Polymeric scaffolds for cardiac tissue engineering: requirements and fabrication technologies, Polym. Int. 63 (2014) 2-11.

[28] L. Persano, A. Camposeo, C. Tekmen, D. Pisignano, Industrial upscaling of electrospinning and applications of polymer nanofibers: a review, Macromol. Mater. Eng. 298 (2013) 504-520.

[29] S. Khorshidi, A. Solouk, H. Mirzadeh, S. Mazinani, J.M. Lagaron, S. Sharifi, S. Ramakrishna, A review of key challenges of electrospun scaffolds for tissueengineering applications, J. Tissue Eng. Regen. Med. 10 (2016) 715-738.

[30] Y. Tang, L. Liu, J. Li, L. Yu, L. Wang, J. Shi, Y. Chen, Induction and differentiation of human induced pluripotent stem cells into functional cardiomyocytes on a compartmented monolayer of gelatin nanofibers, Nanoscale 8 (2016) 14530 14540.

[31] Y. Tang, L. Liu, J. Li, L. Yu, F.P.U. Severino, L. Wang, J. Shi, X. Tu, V. Torre, Y. Chen, Effective motor neuron differentiation of hiPSCs on a patch made of crosslinked monolayer gelatin nanofibers, J. Mater. Chem. B 4 (2016) 33053312.

[32] N.J. Kaiser, K.L.K. Coulombe, Physiologically inspired cardiac scaffolds for tailored in vivo function and heart regeneration, Biomed. Mater. 10 (2015) 34003.

[33] A.K. Capulli, L.A. MacQueen, S.P. Sheehy, K.K. Parker, Fibrous scaffolds for building hearts and heart parts, Adv. Drug Deliv. Rev. 96 (2016) 83-102.

[34] G. Macchiarelli, O. Ohtani, S.A. Nottola, T. Stallone, A. Camboni, I.M. Prado, P. M. Motta, A micro-anatomical model of the distribution of myocardial endomysial collagen, Histol. Histopathol. 17 (2002) 699-706.

[35] G.C. Engelmayr, M. Cheng, C.J. Bettinger, J.T. Borenstein, R. Langer, L.E. Freed, Accordion-like honeycombs for tissue engineering of cardiac anisotropy, Nat. Mater. 7 (2008) 1003-1010.

[36] H.N. Kim, A. Jiao, N.S. Hwang, M.S. Kim, D.H. Kang, D.H. Kim, K.Y. Suh, Nanotopography-guided tissue engineering and regenerative medicine, Adv. Drug Deliv. Rev. 65 (2013) 536-558.

[37] Y. Li, G. Huang, X. Zhang, L. Wang, Y. Du, T.J. Lu, F. Xu, Engineering cell alignment in vitro, Biotechnol. Adv. 32 (2014) 347-365.

[38] Q.-Z. Chen, A. Bismarck, U. Hansen, S. Junaid, M.Q. Tran, S.E. Harding, N.N. Ali, A.R. Boccaccini, Characterisation of a soft elastomer poly(glycerol sebacate) designed to match the mechanical properties of myocardial tissue, Biomaterials 29 (2008) 47-57.

[39] A.J. Engler, C. Carag-Krieger, C.P. Johnson, M. Raab, H.-Y. Tang, D.W. Speicher, J.W. Sanger, J.M. Sanger, D.E. Discher, Embryonic cardiomyocytes beat best on a matrix with heart-like elasticity: scar-like rigidity inhibits beating, J. Cell Sci. 121 (2008) 3794-3802.

[40] R.R. Chaturvedi, T. Herron, R. Simmons, D. Shore, P. Kumar, B. Sethia, F. Chua, E. Vassiliadis, J.C. Kentish, Passive stiffness of myocardium from congenital heart disease and implications for diastole, Circulation 121 (2010) 979-988.

[41] W.C. Nelson, C.-J. Kim, Droplet actuation by electrowetting-on-dielectric (EWOD): a review, J. Adhes. Sci. Technol. 26 (2012) 1-25.

[42] D.M. Pedrotty, Engineering skeletal myoblasts: roles of three-dimensional culture and electrical stimulation, AJP Hear. Circ. Physiol. 288 (2004) H1620H1626.
[43] D. Kai, M.P. Prabhakaran, G. Jin, S. Ramakrishna, Polypyrrole-contained electrospun conductive nanofibrous membranes for cardiac tissue engineering, J. Biomed. Mater. Res., Part A 99 (2011) 376-385.

[44] N. Tandon, C. Cannizzaro, P.P.-H.G. Chao, R. Maidhof, A. Marsano, H.T.H. Au, M. Radisic, G. Vunjak-Novakovic, Electrical stimulation systems for cardiac tissue engineering, Nat. Protoc. 4 (2009) 155-173.

[45] T. Dvir, B.P. Timko, M.D. Brigham, S.R. Naik, S.S. Karajanagi, O. Levy, H. Jin, K.K. Parker, R. Langer, D.S. Kohane, Nanowired three-dimensional cardiac patches, Nat. Nanotechnol. 6 (2011) 720-725.

[46] E. Mooney, J.N. Mackle, D.J.-P. Blond, E. O'Cearbhaill, G. Shaw, W.J. Blau, F.P. Barry, V. Barron, J.M. Murphy, The electrical stimulation of carbon nanotubes to provide a cardiomimetic cue to MSCs, Biomaterials 33 (2012) 6132-6139.

[47] K. Hanee, N. Lila, S. Benadda, F. Legrand, A. Carpentier, J.C. Chachques, Development of bioartificial myocardium by electrostimulation of 3D collagen scaffolds seeded with stem cells, Heart Int. 7 (2012).

[48] M. Generali, P.E. Dijkman, S.P. Hoerstrup, Bioresorbable scaffolds for cardiovascular tissue engineering, EMJ Interv. Cardiol. 1 (2014) 91-99.

[49] N. Bursac, M. Papadaki, J.A. White, S.R. Eisenberg, G. Vunjak-Novakovic, L.E Freed, Cultivation in rotating bioreactors promotes maintenance of cardiac myocyte electrophysiology and molecular properties, Tissue Eng. 9 (2003) 1243-1253.

[50] M. Radisic, A. Marsano, R. Maidhof, Y. Wang, G. Vunjak-Novakovic, Cardiac tissue engineering using perfusion bioreactor systems, Nat. Protoc. 3 (2008) 719-738.

[51] M. Tehranirokh, A.Z. Kouzani, P.S. Francis, J.R. Kanwar, Microfluidic devices for cell cultivation and proliferation, Biomicrofluidics 7 (2013) 51502

[52] S. Ramakrishna, K. Fujihara, W.-E. Teo, T.-C. Lim, Z. Ma, An introduction to electrospinning and nanofibers, World Sci. (2005), http://dx.doi.org/10.1142/ 5894.

[53] Z.-M. Huang, Y.-Z. Zhang, M. Kotaki, S. Ramakrishna, A review on polymer nanofibers by electrospinning and their applications in nanocomposites, Compos. Sci. Technol. 63 (2003) 2223-2253.

[54] N. Bhattarai, Z. Li, J. Gunn, M. Leung, A. Cooper, D. Edmondson, O. Veiseh, M.H. Chen, Y. Zhang, R.G. Ellenbogen, M. Zhang, Natural-synthetic polyblend nanofibers for biomedical applications, Adv. Mater. 21 (2009) 2792-2797.

[55] J. Xie, S.M. Willerth, X. Li, M.R. Macewan, A. Rader, S.E. Sakiyama-Elbert, Y. Xia, The differentiation of embryonic stem cells seeded on electrospun nanofibers into neural lineages, Biomaterials 30 (2008) 354-362.

[56] B. Oh, C.H. Lee, Nanofiber for cardiovascular tissue engineering, Expert Opin. Drug Deliv. 10 (2013) 1565-1582.

[57] G. Zhao, X. Zhang, T.J. Lu, F. Xu, Recent advances in electrospun nanofibrous scaffolds for cardiac tissue engineering, Adv. Funct. Mater. 25 (2015) 5726 5738.

[58] S.A. Sell, M.J. McClure, K. Garg, P.S. Wolfe, G.L. Bowlin, Electrospinning of collagen/biopolymers for regenerative medicine and cardiovascular tissue engineering, Adv. Drug Deliv. Rev. 61 (2009) 1007-1019.

[59] J.A. Matthews, G.E. Wnek, D.G. Simpson, G.L. Bowlin, Electrospinning of collagen nanofibers, Biomacromolecules 3 (2002) 232-238.

[60] S.Z. Yow, C.H. Quek, E.K.F. Yim, C.T. Lim, K.W. Leong, Collagen-based fibrous scaffold for spatial organization of encapsulated and seeded human mesenchymal stem cells, Biomaterials 30 (2009) 1133-1142.

[61] Z. Kassiri, R. Khokha, Myocardial extra-cellular matrix and its regulation by metalloproteinases and their inhibitors, Thromb Haemost 93 (2005) 212219.

[62] S.D. Zimmerman, W.J. Karlon, J.W. Holmes, J.H. Omens, J.W. Covell, Structural and mechanical factors influencing infarct scar collagen organization, Am. J. Physiol. Heart Circ. Physiol. 278 (2000) H194-H200.

[63] M. Kitsara, P. Joanne, S.E. Boitard, I. Ben Dhiab, B. Poinard, P. Menasché, C. Gagnieu, P. Forest, O. Agbulut, Y. Chen, Fabrication of cardiac patch by using electrospun collagen fibers, Microelectron. Eng. 144 (2015) 46-50.

[64] P. Joanne, M. Kitsara, S.E. Boitard, H. Naemetalla, V. Vanneaux, M. Pernot, ]. Larghero, P. Forest, Y. Chen, P. Menasché, O. Agbulut, Nanofibrous clinicalgrade collagen scaffolds seeded with human cardiomyocytes induces cardiac remodeling in dilated cardiomyopathy, Biomaterials 80 (2016) 157-168.

[65] A. Sahni, C.W. Francis, Vascular endothelial growth factor binds to fibrinogen and fibrin and stimulates endothelial cell proliferation, Blood 96 (2000) 3772-3778.

[66] M.C. McManus, E.D. Boland, D.G. Simpson, C.P. Barnes, G.L. Bowlin, Electrospun fibrinogen: feasibility as a tissue engineering scaffold in a rat cell culture model, J. Biomed. Mater. Res. - Part A 81 (2007) 299-309.

[67] H. Homayoni, S. Abdolkarim, H. Ravandi, M. Valizadeh, Electrospinning of chitosan nanofibers: processing optimization, Carbohydr. Polym. 77 (2009) 656-661.

[68] A. Hussain, G. Collins, D. Yip, C.H. Cho, Functional 3-D cardiac co-culture model using bioactive chitosan nanofiber scaffolds, Biotechnol. Bioeng. 110 (2013) 637-647.

[69] U.R. Rodgers, A.S. Weiss, Cellular interactions with elastin, Pathol. Biol. 53 (2005) 390-398.

[70] E.D. Boland, Electrospinning collagen and elastin: preliminary vascular tissue engineering, Front. Biosci. 9 (2004) 1422.

[71] X. Zhang, C.B. Baughman, D.L. Kaplan, In vitro evaluation of electrospun silk fibroin scaffolds for vascular cell growth, Biomaterials 29 (2008) 2217-2227.

[72] P. Balasubramanian, M.P. Prabhakaran, D. Kai, S. Ramakrishna, Human cardiomyocyte interaction with electrospun fibrinogen/gelatin nanofibers for myocardial regeneration, J. Biomater. Sci. Polym. Ed. 24 (2013) 1660-1675. 
[73] S. Fleischer, A. Shapira, O. Regev, N. Nseir, E. Zussman, T. Dvir, Albumin fiber scaffolds for engineering functional cardiac tissues, Biotechnol. Bioeng. 111 (2014) 1246-1257.

[74] M. Shin, O. Ishii, T. Sueda, J.P. Vacanti, Contractile cardiac grafts using a novel nanofibrous mesh, Biomaterials 25 (2004) 3717-3723.

[75] O. Ishii, M. Shin, T. Sueda, J.P. Vacanti, In vitro tissue engineering of a cardiac graft using a degradable scaffold with an extracellular matrix-like topography, J. Thorac. Cardiovasc. Surg. 130 (2005) 1358-1363.

[76] M.P. Prabhakaran, J. Venugopal, D. Kai, S. Ramakrishna, Biomimetic material strategies for cardiac tissue engineering, Mater. Sci. Eng., C 31 (2011) 503513.

[77] S.G. Kumbar, R. James, S.P. Nukavarapu, C.T. Laurencin, Electrospun nanofiber scaffolds: engineering soft tissues, Biomed. Mater. 3 (2008) 34002-34015.

[78] J. Venugopal, Y.Z. Zhang, S. Ramakrishna, Fabrication of modified and functionalized polycaprolactone nanofibre scaffolds for vascular tissue engineering, Nanotechnology 16 (2005) 2138-2142.

[79] S. Heydarkhan-Hagvall, K. Schenke-Layland, A.P. Dhanasopon, F. Rofail, H. Smith, B.M. Wu, R. Shemin, R.E. Beygui, W.R. MacLellan, Three-dimensional electrospun ECM-based hybrid scaffolds for cardiovascular tissue engineering, Biomaterials 29 (2008) 2907-2914.

[80] D. Kai, M.P. Prabhakaran, G. Jin, S. Ramakrishna, Guided orientation of cardiomyocytes on electrospun aligned nanofibers for cardiac tissue engineering, J. Biomed. Mater. Res. Part B Appl. Biomater. 98 (2011) 379-386.

[81] C. Srinivasa Reddy, J. Reddy Venugopal, S. Ramakrishna, E. Zussman, Polycaprolactone/oligomer compound scaffolds for cardiac tissue engineering, J. Biomed. Mater. Res. - Part A 102 (2014) 3713-3725.

[82] C.S. Reddy, A. Arinstein, R. Avrahami, E. Zussman, Fabrication of thermoset polymer nanofibers by co-electrospinning of uniform core-shell structures, J. Mater. Chem. 19 (2009) 7198-7201.

[83] Y. Chen, D. Zeng, L. Ding, X.-L. Li, X.-T. Liu, W.-J. Li, T. Wei, S. Yan, J.-H. Xie, L. Wei, Q.-S. Zheng, Three-dimensional poly-( $\varepsilon$-caprolactone) nanofibrous scaffolds directly promote the cardiomyocyte differentiation of murineinduced pluripotent stem cells through Wnt/ $\beta$-catenin signaling, BMC Cell Biol. 16 (2015) 22

[84] S. Fleischer, R. Feiner, A. Shapira, J. Ji, X. Sui, H. Daniel Wagner, T. Dvir, Springlike fibers for cardiac tissue engineering, Biomaterials 34 (2013) 8599-8606.

[85] A.G. Guex, A. Frobert, J. Valentin, G. Fortunato, D. Hegemann, S. Cook, T.P. Carrel, H.T. Tevaearai, M.N. Giraud, Plasma-functionalized electrospun matrix for biograft development and cardiac function stabilization, Acta Biomater. 10 (2014) 2996-3006.

[86] S. Jana, A. Lerman, R.D. Simari, In vitro model of a fibrosa layer of a heart valve, ACS Appl. Mater. Interf. 7 (2015) 20012-20020.

[87] X. Zong, H. Bien, C.-Y. Chung, L. Yin, D. Fang, B.S. Hsiao, B. Chu, E. Entcheva, Electrospun fine-textured scaffolds for heart tissue constructs, Biomaterials 26 (2005) 5330-5338.

[88] M. Li, M.J. Mondrinos, X. Chen, M.R. Gandhi, F.K. Ko, P.I. Lelkes, Co-electrospun poly(lactide-co-glycolide), gelatin, and elastin blends for tissue engineering scaffolds, J. Biomed. Mater. Res. - Part A 79 (2006) 963-973.

[89] H. Hosseinkhani, M. Hosseinkhani, S. Hattori, R. Matsuoka, N. Kawaguchi, Micro and nano-scale in vitro 3D culture system for cardiac stem cells, J. Biomed. Mater. Res. 94 (2010) 1-8.

[90] L. Zakharova, H. Nural-Guvener, L. Feehery, S. Popovic-Sljukic, M.A. Gaballa Transplantation of epigenetically modified adult cardiac c-kit+ cells retards remodeling and improves cardiac function in ischemic heart failure model, Stem Cells Transl. Med. 4 (2015) 1086-1096.

[91] J.H. van Berlo, O. Kanisicak, M. Maillet, R.J. Vagnozzi, J. Karch, S.-C.J. Lin, R.C. Middleton, E. Marbán, J.D. Molkentin, C-kit+ cells minimally contribute cardiomyocytes to the heart, Nature 509 (2014) 337-341.

[92] M. Khan, Y. Xu, S. Hua, J. Johnson, A. Belevych, P.M.L. Janssen, S. Gyorke J. Guan, M.G. Angelos, Evaluation of changes in morphology and function of human induced pluripotent stem cell derived cardiomyocytes (hiPSCCMs) cultured on an aligned-nanofiber cardiac patch, PLOS ONE 10 (2015) 1-19.

[93] M.P. Prabhakaran, L.G. Mobarakeh, D. Kai, K. Karbalaie, M.H. Nasr-Esfahani, S. Ramakrishna, Differentiation of embryonic stem cells to cardiomyocytes on electrospun nanofibrous substrates, J. Biomed. Mater. Res. - Part B Appl. Biomater. 102 (2014) 447-454.

[94] S. Mukherjee, C. Gualandi, M.L. Focarete, R. Ravichandran, J.R. Venugopal, M. Raghunath, S. Ramakrishna, Elastomeric electrospun scaffolds of poly(L lactide-co-trimethylene carbonate) for myocardial tissue engineering, J Mater. Sci. - Mater. Med. 22 (2011) 1689-1699.

[95] R.M. Aghdam, S. Shakhesi, S. Najarian, M.M. Mohammadi, S.H. Ahmadi Tafti, H. Mirzadeh, Fabrication of a nanofibrous scaffold for the in vitro culture of cardiac progenitor cells for myocardial regeneration, Int. J. Polym. Mater Polym. Biomater. 63 (2014) 229-239.

[96] M.P. Prabhakaran, A.S. Nair, D. Kai, S. Ramakrishna, Electrospun composite scaffolds containing poly(octanediol-co-citrate) for cardiac tissue engineering, Biopolymers 97 (2012) 529-538.

[97] S. Hinderer, J. Seifert, M. Votteler, N. Shen, J. Rheinlaender, T.E. Schäffer, K. Schenke-Layland, Engineering of a bio-functionalized hybrid off-the-shelf heart valve, Biomaterials 35 (2014) 2130-2139.

[98] R. Lakshmanan, U.M. Krishnan, S. Sethuraman, Multidimensional nanofibrous scaffolds of poly(lactide-co-caprolactone) and poly(ethyl oxazoline) with improved features for cardiac tissue engineering, Nanomedicine 10 (2015) 3451-3467.
[99] D.N. Rockwood, R.E. Akins, I.C. Parrag, K.A. Woodhouse, J.F. Rabolt, Culture on electrospun polyurethane scaffolds decreases atrial natriuretic peptide expression by cardiomyocytes in vitro, Biomaterials 29 (2008) 4783-4791.

[100] J.D. Fromstein, P.W. Zandstra, C. Alperin, D. Rockwood, J.F. Rabolt, K.A. Woodhouse, Seeding bioreactor-produced embryonic stem cell-derived cardiomyocytes on different porous, degradable, polyurethane scaffolds reveals the effect of scaffold architecture on cell morphology, Tissue Eng. Part A 14 (2008) 369-378.

[101] I.C. Parrag, P.W. Zandstra, K.A. Woodhouse, Fiber alignment and coculture with fibroblasts improves the differentiated phenotype of murine embryonic stem cell-derived cardiomyocytes for cardiac tissue engineering, Biotechnol. Bioeng. 109 (2012) 813-822.

[102] J.J. Stankus, J. Guan, K. Fujimoto, W.R. Wagner, Microintegrating smooth muscle cells into a biodegradable, elastomeric fiber matrix, Biomaterials 27 (2006) 735-744.

[103] T. Courtney, M.S. Sacks, J. Stankus, J. Guan, W.R. Wagner, Design and analysis of tissue engineering scaffolds that mimic soft tissue mechanical anisotropy, Biomaterials 27 (2006) 3631-3638.

[104] N.J. Amoroso, A. D'Amore, Y. Hong C.P. Rivera, M.S. Sacks, W.R. Wagner, Microstructural manipulation of electrospun scaffolds for specific bending stiffness for heart valve tissue engineering, Acta Biomater. 8 (2012) 42684277.

[105] C.M. Hobson, N.J. Amoroso, R. Amini, E. Ungchusri, Y. Hong, A. D'amore, M.S Sacks, W.R. Wagner, Fabrication of elastomeric scaffolds with curvilinear fibrous structures for heart valve leaflet engineering, J. Biomed. Mater. Res. Part A 103 (2015) 3101-3106.

[106] H.G. Senel Ayaz, A. Perets, H. Ayaz, K.D. Gilroy, M. Govindaraj, D. Brookstein, P.I. Lelkes, Textile-templated electrospun anisotropic scaffolds for regenerative cardiac tissue engineering, Biomaterials 35 (2014) 8540-8552.

[107] P.-H. Chen, H.-C. Liao, S.-H. Hsu, R.-S. Chen, M.-C. Wu, Y.-F. Yang, C.-C. Wu, M.-H. Chen, W.-F. Su, A novel polyurethane/cellulose fibrous scaffold for cardiac tissue engineering, RSC Adv. 5 (2015) 6932-6939.

[108] R. Rai, M. Tallawi, A. Grigore, A.R. Boccaccini, Synthesis, properties and biomedical applications of poly(glycerol sebacate) (PGS): a review, Prog. Polym. Sci. 37 (2012) 1051-1078.

[109] R. Ravichandran, J.R. Venugopal, S. Sundarrajan, S. Mukherjee, S. Ramakrishna, Poly(glycerol sebacate)/gelatin core/shell fibrous structure for regeneration of myocardial infarction, Tissue Eng. Part A 17 (2011) 13631373.

[110] M. Kharaziha, M. Nikkhah, S.R. Shin, N. Annabi, N. Masoumi, A.K. Gaharwar, G. Camci-Unal, A. Khademhosseini, PGS: Gelatin nanofibrous scaffolds with tunable mechanical and structural properties for engineering cardiac tissues, Biomaterials 34 (2013) 6355-6366.

[111] H. Kenar, G.T. Kose, M. Toner, D.L. Kaplan, V. Hasirci, A 3D aligned microfibrous myocardial tissue construct cultured under transient perfusion, Biomaterials 32 (2011) 5320-5329.

[112] B. Xu, Y. Li, X. Fang, G.A. Thouas, W.D. Cook, D.F. Newgreen, Q. Chen, Mechanically tissue-like elastomeric polymers and their potential as a vehicle to deliver functional cardiomyocytes, J. Mech. Behav. Biomed. Mater. 28 (2013) 354-365.

[113] M. Tallawi, D.C. Zebrowski, R. Rai, J.A. Roether, D.W. Schubert, M. El Fray, F.B. Engel, K.E. Aifantis, A.R. Boccaccini, Poly(glycerol sebacate)/poly(butylene succinate-butylene dilinoleate) fibrous scaffolds for cardiac tissue engineering, Tissue Eng. Part C Meth. 21 (2015) 585-596.

[114] D. Castellano, M. Blanes, B. Marco, I. Cerrada, A. Ruiz-Saurí, B. Pelacho, M. Araña, J.A. Montero, V. Cambra, F. Prosper, P. Sepúlveda, A comparison of electrospun polymers reveals poly(3-hydroxybutyrate) fiber as a superior scaffold for cardiac repair, Stem Cells Dev. 23 (2014) 1479-1490.

[115] M. Letizia Focarete, C. Gualandi, M. Scandola, M. Govoni, E. Giordano, L. Foroni, S. Valente, G. Pasquinelli, W. Gao, R.A. Gross, Electrospun scaffolds of a polyhydroxyalkanoate consisting of $\omega$-hydroxylpentadecanoate repeat units: fabrication and in vitro biocompatibility studies, gross, J. Biomater. Sci. Polym. Ed. J. Biomater. Sci. J. Biomater. Sci. 21 (2010) 1283-1296.

[116] D. Kalfa, A. Bel, A. Chen-Tournoux, A. Della Martina, P. Rochereau, C. Coz, V. Bellamy, M. Bensalah, V. Vanneaux, S. Lecourt, E. Mousseaux, P. Bruneval, J. Larghero, P. Menasché, A polydioxanone electrospun valved patch to replace the right ventricular outflow tract in a growing lamb model, Biomaterials 31 (2010) 4056-4063.

[117] M. Pontailler, E. Illangakoon, G.R. Williams, C. Marijon, V. Bellamy, D. Balvay, G. Autret, V. Vanneaux, J. Larghero, V. Planat-Benard, M.-C. Perier, P. Bruneval, P. Menasché, D. Kalfa, Polymer-based reconstruction of the inferior vena cava in rat: stem cells or RGD peptide?. Tissue Eng Part A 21 (2015) 1552-1564.

[118] M. Sireesha, V. Jagadeesh Babu, S. Ramakrishna, Biocompatible and biodegradable elastomer/fibrinogen composite electrospun scaffolds for cardiac tissue regeneration, RSC Adv. 5 (2015) 103308-103314.

[119] A. Townsend-Nicholson, S.N. Jayasinghe, Cell electrospinning: a unique biotechnique for encapsulating living organisms for generating active biological microthreads/scaffolds, Biomacromolecules 7 (2006) 3364-3369.

[120] E. Ehler, S.N. Jayasinghe, Cell electrospinning cardiac patches for tissue engineering the heart, Analyst 139 (2014) 4449-4452.

[121] J. Yu, A. Lee, W.-H. Lin, C. Lin, Y. Wu, W. Tsai, Electrospun PLGA fibers incorporated with functionalized biomolecules for cardiac tissue engineering, Tissue Eng. Part A 20 (2014) 1896-1907.

[122] C. Spadaccio, A. Rainer, M. Trombetta, M. Centola, M. Lusini, M. Chello, E. Covino, F. De Marco, R. Coccia, Y. Toyoda, J.A. Genovese, A G-CSF 
functionalized scaffold for stem cells seeding: a differentiating device for cardiac purposes, J. Cell Mol. Med. 15 (2011) 1096-1108.

[123] V. Bhaarathy, J. Venugopal, C. Gandhimathi, N. Ponpandian, D. Mangalaraj, S. Ramakrishna, Biologically improved nanofibrous scaffolds for cardiac tissue engineering, Mater. Sci. Eng., C 44 (2014) 268-277.

[124] T. Simón-Yarza, A. Rossi, K.-H. Heffels, F. Prósper, J. Groll, M.J. Blanco-Prieto, Polymeric electrospun scaffolds: neuregulin encapsulation and biocompatibility studies in a model of myocardial ischemia, Tissue Eng. Part A 21 (2015) 1654-1661.

[125] L. Tian, M.P. Prabhakaran, X. Ding, D. Kai, S. Ramakrishna, Emulsion electrospun vascular endothelial growth factor encapsulated poly(L-lactic acid-co- $\varepsilon$-caprolactone) nanofibers for sustained release in cardiac tissue engineering, J. Mater. Sci. 47 (2012) 3272-3281.

[126] R. Ravichandran, J.R. Venugopal, S. Mukherjee, S. Sundarrajan, S. Ramakrishna, Elastomeric core/shell nanofibrous cardiac patch as a biomimetic support for infarcted porcine myocardium, Tissue Eng. Part A 21 (2015) 1288-1298

[127] H.-J. Chung, J.-T. Kim, H.-J. Kim, H.-W. Kyung, P. Katila, J.-H. Lee, T.-H. Yang, Y.-I. Yang, S.-J. Lee, Epicardial delivery of VEGF and cardiac stem cells guided by 3-dimensional PLLA mat enhancing cardiac regeneration and angiogenesis in acute myocardial infarction, J. Control. Release 205 (2015) 218-230.

[128] A. Andukuri, C. Anakwenze, B. Blakeney, H.-W. Jun, Native endotheliummimicking nanomatrices and applications, in: Nanomedicine Cardiovasc. Syst., Science Publishers, 2011, pp. 221-238.

[129] Y.Z. Zhang, C.T. Lim, The development of biocomposite nanofibers for tissue scaffolding applications, JOM 60 (2008) 45-48.

[130] P.-H. Kim, J.-Y. Cho, Myocardial tissue engineering using electrospun nanofiber composites, BMB Rep. 49 (2016) 26-36.

[131] B. Leobon, I. Garcin, P. Menasche, J.-T. Vilquin, E. Audinat, S. Charpak, Myoblasts transplanted into rat infarcted myocardium are functionally isolated from their host, Proc. Natl. Acad. Sci. USA 100 (2003) 78087811.

[132] S.R. Shin, S.M. Jung M. Zalabany, K. Kim, P. Zorlutuna, S. bok Kim, M. Nikkhah, M. Khabiry, M. Azize, J. Kong, K. Wan, T. Palacios, M.R. Dokmeci, H. Bae, X. (Shirley) Tang, A. Khademhosseini, Carbon-nanotube-embedded hydrogel sheets for engineering cardiac constructs and bioactuators, ACS Nano 7 (2013) 2369-2380.

[133] S.K. Smart, A.I. Cassady, G.Q. Lu, D.J. Martin, The biocompatibility of carbon nanotubes, Carbon N.Y. 44 (2006) 1034-1047

[134] S. Crowder, Y. Liang, R. Rath, A. Park, Poly ( $\varepsilon$-caprolactone)-carbon nanotube composite scaffolds for enhanced cardiac differentiation of human mesenchymal stem cells, Nanomedicine 8 (2013) 1-20.

[135] M. Kharaziha, S.R. Shin, M. Nikkhah, S.N. Topkaya, N. Masoumi, N. Annabi, M. R. Dokmeci, A. Khademhosseini, Tough and flexible CNT-polymeric hybrid scaffolds for engineering cardiac constructs, Biomaterials 35 (2014) 73467354.

[136] S. Fleischer, M. Shevach, R. Feiner, T. Dvir, Coiled fiber scaffolds embedded with gold nanoparticles improve the performance of engineered cardiac tissues, Nanoscale 6 (2014) 9410-9414.

[137] R. Ravichandran, R. Sridhar, J.R. Venugopal, S. Sundarrajan, S. Mukherjee, S. Ramakrishna, Gold nanoparticle loaded hybrid nanofibers for cardiogenic differentiation of stem cells for infarcted myocardium regeneration, Macromol. Biosci. 14 (2014) 515-525.

[138] S. Sridhar, J.R. Venugopal, R. Sridhar, S. Ramakrishna, Cardiogenic differentiation of mesenchymal stem cells with gold nanoparticle loaded functionalized nanofibers, Colloids Surf. B. Biointerfaces 134 (2015) 346-354.

[139] D. Jung, I. Minami, S. Patel, J. Lee, B. Jiang, Q. Yuan, L. Li, S. Kobayashi, Y. Chen, K.-B. Lee, N. Nakatsuji, Incorporation of functionalized gold nanoparticles into nanofibers for enhanced attachment and differentiation of mammalian cells, J. Nanobiotechnol. 10 (2012) 23.

[140] C.W. Hsiao, M.Y. Bai, Y. Chang, M.F. Chung T.Y. Lee, C.T. Wu, B. Maiti, Z.X. Liao, R.K. Li, H.W. Sung, Electrical coupling of isolated cardiomyocyte clusters grown on aligned conductive nanofibrous meshes for their synchronized beating, Biomaterials 34 (2013) 1063-1072.

[141] A. Borriello, V. Guarino, L. Schiavo, M.A. Alvarez-Perez, L. Ambrosio, Optimizing PANi doped electroactive substrates as patches for the regeneration of cardiac muscle, J. Mater. Sci. - Mater. Med. 22 (2011) 1053-1062.

[142] D. Kai, M.P. Prabhakaran, G. Jin, S. Ramakrishna, Polypyrrole-contained electrospun conductive nanofibrous membranes for cardiac tissue engineering, J. Biomed. Mater. Res. - Part A 99A (2011) 376-385.
[143] M. Li, Y. Guo, Y. Wei, A.G. MacDiarmid, P.I. Lelkes, Electrospinning polyaniline-contained gelatin nanofibers for tissue engineering applications, Biomaterials 27 (2006) 2705-2715.

[144] E.G.R. Fernandes, V. Zucolotto, A.A.A. De Queiroz, Electrospinning of hyperbranched poly-t-lysine/polyaniline nanofibers for application in cardiac tissue engineering, J. Macromol. Sci. Part A 47 (2010) 1203-1207.

[145] C.-L. Zhang, S.-H. Yu, Nanoparticles meet electrospinning: recent advances and future prospects, Chem. Soc. Rev. 43 (2014) 4423.

[146] R. Zhou, H. Gao, Cytotoxicity of graphene: recent advances and future perspective, Wiley Interdiscip. Rev. Nanomed. Nanobiotechnol. 6 (2014) 452 474.

[147] L. Yildirimer, N.T.K. Thanh, M. Loizidou, A.M. Seifalian, Toxicology and clinical potential of nanoparticles, Nano Today 6 (2011) 585-607.

[148] A. Elsaesser, C.V. Howard, Toxicology of nanoparticles, Adv. Drug Deliv. Rev. 64 (2012) 129-137.

[149] H.S. Yoo, T.G. Kim, T.G. Park, Surface-functionalized electrospun nanofibers for tissue engineering and drug delivery, Adv. Drug Deliv. Rev. 61 (2009) 1033-1042.

[150] M. Shevach, B.M. Maoz, R. Feiner, A. Shapira, T. Dvir, Nanoengineering gold particle composite fibers for cardiac tissue engineering, J. Mater. Chem. B 1 (2013) 5210.

[151] L. Jin, T. Wang, Z.-Q. Feng, M. Zhu, M.K. Leach, Y.I. Naim, Q. Jiang, Fabrication and characterization of a novel fluffy polypyrrole fibrous scaffold designed for 3D cell culture, J. Mater. Chem. 22 (2012) 18321.

[152] Y.M. Shin, H. Park, H. Shin, Enhancement of cardiac myoblast responses onto electrospun PLCL fibrous matrices coated with polydopamine for gelatin immobilization, Macromol. Res. 19 (2011) 835-842.

[153] S. Fleischer, J. Miller, H. Hurowitz, A. Shapira, T. Dvir, Effect of fiber diameter on the assembly of functional 3D cardiac patches, Nanotechnology 26 (2015) 291002.

[154] M.R. Badrossamay, H.A. Mcllwee, J.A. Goss, K.K. Parker, Nanofiber assembly by rotary jet-spinning, Nano Lett. 10 (2010) 2257-2261.

[155] F. Chen, C.N. Lee, S.H. Teoh, Nanofibrous modification on ultra-thin poly(ecaprolactone) membrane via electrospinning, Mater. Sci. Eng., C 27 (2007) $325-332$.

[156] Y. Zhu, C. Gao, X. Liu, J. Shen, Surface modification of polycaprolactone membrane via aminolysis and biomacromolecule immobilization for promoting cytocompatibility of human endothelial cells, Biomacromolecules 3 (2002) 1312-1319.

[157] D. Kontziampasis, K. Beltsios, E. Tegou, P. Argitis, E. Gogolides, Optimized surface silylation of chemically amplified epoxidized photoresists for micromachining applications, J. Appl. Polym. Sci. 117 (2010) 2189-2195.

[158] L. Duque Sánchez, N. Brack, A. Postma, P.J. Pigram, L. Meagher, Surface modification of electrospun fibres for biomedical applications: a focus on radical polymerization methods, Biomaterials 106 (2016) 24-45.

[159] A. Bourkoula, V. Constantoudis, D. Kontziampasis, P.S. Petrou, S.E. Kakabakos A. Tserepi, E. Gogolides, Roughness threshold for cell attachment and proliferation on plasma micro-nanotextured polymeric surfaces: the case of primary human skin fibroblasts and mouse immortalized 3T3 fibroblasts, J. Phys. D. Appl. Phys. 49 (2016) 304002.

[160] D. Kontziampasis, T. Trantidou, A. Regoutz, E.J. Humphrey, D. Carta, C.M. Terracciano, T. Prodromakis, Effects of Ar and $\mathrm{O} 2$ plasma etching on parylene C: topography versus surface chemistry and the impact on cell viability, Plasma Process. Polym. 13 (2016) 324-333.

[161] E. Gogolides, V. Constantoudis, G. Kokkoris, D. Kontziampasis, K. Tsougeni, G. Boulousis, M. Vlachopoulou, A. Tserepi, Controlling roughness: from etching to nanotexturing and plasma-directed organization on organic and inorganic materials, J. Phys. D Appl. Phys. 44 (2011) 174021.

[162] D. Kontziampasis, M. Kitsara, Polymer surface modification: plasma for applications, Encycl. Plasma Technol. (2016) (in press), http://dx.doi.org/10. 1081/E-EPLT-120053913.

[163] M. Kitsara, P. Petrou, D. Kontziampasis, K. Misiakos, E. Makarona, I. Raptis, K. Beltsios, Biomolecular layer thickness evaluation using white light reflectance spectroscopy, Microelectron. Eng. 87 (2010) 802-805.

[164] D. Kontziampasis, V. Constantoudis, E. Gogolides, Plasma directed organization of nanodots on polymers: effects of polymer type and etching time on morphology and order, Plasma Process. Polym. 9 (2012) 866-872.

[165] N. Vourdas, D. Kontziampasis, G. Kokkoris, V. Constantoudis, A. Goodyear, A Tserepi, M. Cooke, E. Gogolides, Plasma directed assembly and organization: bottom-up nanopatterning using top-down technology, Nanotechnology 21 (2010) 85302. 